Illinois State University

ISU ReD: Research and eData

Theses and Dissertations

6-15-2018

\title{
Emotional Overtones Of Professional Jargon As Experienced By English And Bilingual Speakers
}

Daisy Bueno

Illinois State University, daisybueno2@gmail.com

Follow this and additional works at: https://ir.library.illinoisstate.edu/etd

Part of the Psychology Commons

\section{Recommended Citation}

Bueno, Daisy, "Emotional Overtones Of Professional Jargon As Experienced By English And Bilingual Speakers" (2018). Theses and Dissertations. 950.

https://ir.library.illinoisstate.edu/etd/950

This Dissertation is brought to you for free and open access by ISU ReD: Research and eData. It has been accepted for inclusion in Theses and Dissertations by an authorized administrator of ISU ReD: Research and eData. For more information, please contact ISUReD@ilstu.edu. 


\title{
EMOTIONAL OVERTONES OF PROFESSIONAL JARGON AS EXPERIENCED BY ENGLISH AND BILINGUAL SPEAKERS
}

\author{
Daisy Bueno
}

\section{Pages}

Previous research has suggested that technical language is regularly used in the area of clinical practice called Applied Behavior Analysis (ABA). However, the use of this technical language or jargon may elicit unpleasant emotional responses that could be expected to "turn off" clients or parents of child clients. To understand how emotional overtones of words may interfere with therapist-client communication, the current study utilized an online data collection tool to obtain word emotion ratings of jargon words and terms. The first study is a replication and extension of past research that used existing word emotion ratings for ABA jargon words from a larger corpus of English words. I collected novel emotional ratings of ABA terms and General Psychological terms used in clinical settings. The second study examined emotional responses to ABA terms and General Psychological terms in both English and Spanish by bilingual individuals. Participants completed a word rating task and an acculturation scale that assessed their level of bilingualism. The results of Study 1 are consistent with previous research in finding that $\mathrm{ABA}$ jargon terms were generally perceived as unpleasant. General Psychological terms were found to be just as unpleasant as ABA terms. Although previous research has shown that bilingual individuals may express emotions differently depending on which language they are using at the time, in Study 2 I found that bilingual individuals rated ABA terms and General Psychological terms as largely equivalent with respect to emotional response in both English and 
Spanish. Language dominance and language preference were not correlated with emotional responses to specific terms in either language. Together the results of these studies inform decisions about how to communicate technical information about therapy to individuals seeking support from therapists.

KEYWORDS: Jargon, Applied Behavior Analysis, Word Emotion, Bilingualism 
ENGLISH AND BILINGUAL SPEAKERS

\author{
DAISY BUENO
}

A Dissertation Submitted in Partial

Fulfillment of the Requirements

for the Degree of

DOCTOR OF PHILOSOPHY

Department of Psychology

ILLINOIS STATE UNIVERSITY 
(C) 2018 Daisy Bueno 


\title{
EMOTIONAL OVERTONES OF PROFESSIONAL JARGON AS EXPERIENCED BY ENGLISH AND BILINGUAL SPEAKERS
}

\author{
DAISY BUENO
}

COMMITTEE MEMBERS:

Thomas Critchfield, Co-Chair

Corinne Zimmerman, Co-Chair

Karla J. Doepke

Beth Hatt 


\section{ACKNOWLEDGMENTS}

I wish to thank my committee members, Karla Doepke and Beth Hatt, for their feedback and support on this project. I would especially like to thank my Co-Chairs: Tom Critchfield, for helping me develop my small ideas into this dissertation, and Corinne Zimmerman, for all the "cool-whip" days and nights, all the cookies and coffee, and the endless time and support. I do not think the right words to express my gratitude exist -- I even tried to Google it!

Steve and Jillian, thanks for all the proofreading and for making sure I knew how to count. To all my friends and loved ones, who answered panicked questions, sent me messages of encouragement, and fed me tacos, I owe you billions! I can't forget Lilly and Patton, thanks for all the puppy cuddles!

Ultimamente, le quiero dedicar esta tesis y toda mi educacción a mi familia. Gracias por todo el apoyo y paciencia todos estos años. Todo fue por ustedes y para ustedes.

D.B. 


\section{CONTENTS}

Page

ACKNOWLEDGMENTS

$\begin{array}{lll}\text { CONTENTS } & \text { ii }\end{array}$

FIGURES

CHAPTER I: THE PROBLEM AND ITS BACKGROUND 1

CHAPTER II: REVIEW OF THE LITERATURE 3

Jargon in Applied Behavior Analysis $\quad 3$

Linguistic Diversity Challenges $\quad 7$

Word Emotion $\quad 8$

Emotional Responses to ABA Jargon $\quad 11$

$\begin{array}{ll}\text { The Current Study } & 12\end{array}$

CHAPTER III: STUDY 1

$\begin{array}{ll}\text { Method } & 14\end{array}$

$\begin{array}{ll}\text { Participants } & 14\end{array}$

$\begin{array}{ll}\text { Measures } & 15\end{array}$

$\begin{array}{ll}\text { Procedure } & 17\end{array}$

$\begin{array}{ll}\text { Results } & 19\end{array}$

$\begin{array}{ll}\text { Data Trimming } & 19\end{array}$

$\begin{array}{ll}\text { Research Questions } & 20\end{array}$

$\begin{array}{ll}\text { Study } 1 \text { Discussion } & 27\end{array}$

CHAPTER IV: STUDY 2

Bilingualism and Word Emotion $\quad 32$

$\begin{array}{ll}\text { Method } & 34\end{array}$

Participants $\quad 34$

Measures $\quad 35$

Materials $\quad 36$

Design and Procedures 36

$\begin{array}{ll}\text { Results } & 36\end{array}$ 
$\begin{array}{ll}\text { Study } 2 \text { Discussion } & 40\end{array}$

CHAPTER V: CONCLUSIONS 43

General Discussion $\quad 43$

Strengths and Limitations of the Current Study $\quad 47$

Directions for Future Research $\quad 50$

Clinical Implications $\quad 51$

$\begin{array}{ll}\text { REFERENCES } & 55\end{array}$

$\begin{array}{ll}\text { APPENDIX A: SHORT ACCULTURATION SCALE } & 61\end{array}$

APPENDIX B: INSTRUCTIONS FOR WORD RATING TASK 63

$\begin{array}{ll}\text { APPENDIX C: DEMOGRAPHICS } & 65\end{array}$

$\begin{array}{lr}\text { APPENDIX D: TABLES } & 68\end{array}$ 


\section{FIGURES}

Figure

Page

1. Thirteen ABA words with established norms from the Warriner et al. (2013) corpus that were selected for analysis by Critchfield et al. (2017) and rated in the current study and how they were classified

2. General psychological terms $(n=26)$ with established norms from the Warriner et al. (2013) corpus and the current study and how they were classified

3. ABA terms $(n=36)$ categorized by high and low valence and high and low arousal assigned to each of the four categories of the valence-arousal scatterplot developed by Critchfield et al. (2017)

4. General Psychological terms $(n=33)$ categorized by high and low valence and high and low arousal assigned to each of the four categories of the valence-arousal scatterplot developed by Critchfield et al. (2017)

5. Percentages of ABA technical terms and General Psychological terms that fall into each of the four quadrants of a valence-arousal scatterplot 


\section{CHAPTER I: THE PROBLEM AND ITS BACKGROUND}

Jargon typically refers to the specialized vocabulary that a specific community uses for a more efficient method of communication among themselves. Jargon may help individuals communicate with precision, meaning, and confidence, but jargon terms are typically not clear to those outside the specialized area (Hallenstein, 1978). By using jargon, individuals are able to use a word or short phrase to express an otherwise much longer explanation. Hallenstein also suggested that jargon use in a specialized group gives that community a sense of identity, as it helps identify members of an in-group who shares similar values.

A problem, however, arises when individuals from the in group of a specialized or professional community are required to communicate with individuals who are not a part of the group. Although individuals from a specific in-group may feel more comfortable engaging in conversations with individuals who share their values, beliefs, educational experiences, and technical vocabulary, there is usually a need to communicate with members outside of the group. A well-known example occurs when physicians attempt to interact with their patients (Ha, Anat, \& Longnecker, 2010). Other examples include the need for scientists to communicate with the media, policy makers, and other members of the public (e.g., Goldman \& Bisanz, 2002).

Of particular relevance to the present investigation is the situation that occurs when professional mental health caregivers interact with clients, or with the parents, families, or teachers of child clients (e.g., Elliot, 1988). Such individuals may not understand the technical language used within the specialized areas in mental health (e.g., Applied Behavior Analysis). In such cases, jargon can be a barrier to clear communication, and it can make for a one-directional 
"conversation" that hinders the development of a productive professional relationship with individuals outside of the in-group.

Additionally, it is important to note the continuous changes in demographics of the United States. The Bilingual (Spanish-English speaking) population is growing. As such, there is likely to be an increase in the number of Bilingual clients needing support and mental health services with a corresponding increase in the need for Bilingual therapists. It is therefore important to consider the emotional overtones that specific jargon terms have in each language to encourage the best communication with clients who need support.

In the current study, I directly examined the emotional reactions that individuals have to ABA jargon and General Psychological jargon. Previous research has examined the emotional reactions to jargon using existing corpora. Critchfield, Becirevic, and Reed (2017) suggested that for a more thorough examination of emotional responses, it is important to collect novel ratings of terms. The current study represents an extension of this previous work by collecting novel valence and arousal ratings and comparing the results to previous research. Additionally, Critchfield and Doepke (2018) identified the need for cross-language studies on the acceptance of ABA technical vocabulary. A second study examined the emotional responses Bilingual (Spanish-English) individuals have to mental health technical jargon in both languages.

In the review of the literature I first discuss the use of jargon in ABA. I then discuss linguistic diversity challenges within the field of mental health. I also provide a background on previous word emotion research including previous research related to emotional responses to ABA jargon. 


\section{CHAPTER II: REVIEW OF THE LITERATURE}

\section{Jargon in Applied Behavior Analysis}

Applied Behavior Analysis (ABA) arose in the 1950s and 1960s from basic research on learning and is an approach to human services based on manipulating the environmental context to help increase prosocial behaviors (Ayllon \& Michael, 1959). Contrary to many other approaches that view disordered behavior as a side effect of psychopathological causes or disordered thinking, ABA focuses on experimentally manipulating the environment to directly decrease maladaptive behaviors such as self-injury and aggression (Durand, 1987). The field of ABA exists to remediate problem behavior in a direct, systematic, experimental, and individualized manner and encourage positive social behaviors in society (Baer, Wolf, \& Risley, 1968; Jacobson \& Holburn, 2004).

Although ABA is well established as an effective, evidence-based approach (e.g., National Autism Center, 2015), the image of applied behavior analysts among individuals outside the field is not always a positive one. A variety of observers within the field have suggested that applied behavior analysis has a "marketing problem" (Bailey, 1991, p. 447) in which its practitioners and interventions are viewed as unpleasant and/or undesirable. It is widely thought that one component of this problem is a technical vocabulary that is not user-friendly to individuals outside the field (Bailey, 1991; Foxx, 1996; Lindsley, 1991). For example, Foxx (1996) stated "our desire for precision in language and discourse has led to the perception that we are arrogant and abrasive" (p. 149). Individuals in the field of ABA are notorious for communicating about human behavior with terminology that is understood only by members within the field. For instance, the production and dissemination of data guides the decision- 
making process of individuals in the field of $\mathrm{ABA}$. This focus on empirical data and evidence can lead behavior analysts to speak of "subjects," "control conditions," and "independent variables," and although such terms have precise meanings in the world of behavioral measurement, they may not be perceived by clients (or parents of child clients) as socially acceptable (Bailey, 1991). Specifically, it has been hypothesized that the terminology used to describe the experimental science process can be perceived as cold and manipulative, a suggestion that is broadly consistent with unflattering descriptions of applied behavior analysts by individuals outside the field such as Maurice (1993), whose daughter received ABA therapy.

There are at least two possible reasons for these perceptions. First, individuals who are not familiar with the field of ABA simply may not understand the specific meaning of the technical terms used by practitioners or clinicians in this field, causing them to remain uninformed about what applied behavior analysts propose to do, and why (i.e., it is an "information deficit"). From this perspective, the problem is that jargon lacks meaning. Second, Foxx (1996) pointed out that behavior analysis terms might hold a different meaning to individuals outside the field than they do to individuals in the field of ABA. For example, "punishment" is a term regularly used in the field of ABA to describe a method of decreasing a non-desired behavior. However, as will be explained below, this word typically has different connotations for consumers of ABA interventions.

The reason for conflicting interpretations of technical terms may be traced to the way behavior analysis terms were coined in the first place. Harzem and Miles (1978) pointed out that the language used by behavior analysts has been created by "conceptual revision." Rather than coining new words for technical purposes, behavior analysts have often assigned a new meaning to an existing word (Harzem \& Miles, 1978). Researchers in the field of science education 
discuss a similar problem with the use of labels such as "direct instruction" or "discovery learning" when media outlets report the results of research to the lay public. For instance, Klahr and $\mathrm{Li}$ (2005) stated, "when we adopt a widely used terminology, we are burdened with ensuring that our implementation is consistent with the term's meaning in the educational community" ( $p$. 253). In this example, researchers and media sources translated "direct instruction" to mean "passive learning." Deitz and Arrington (1983) also argued that the words "extinction" and "punishment" are borrowed words with clear technical definitions but rather often unpleasant everyday connotations. In behavior analysis, extinction is the weakening of a behavior that results when reinforcement ceases, but in the public mind, as in biology, extinction is the elimination of a species (Foxx, 1996). In behavior analysis, punishment is when a behaviorcaused event (i.e., consequence) results in that behavior stopping or occurring less often. In everyday language, punishment is used to denote "suffering, pain, or loss that serves as retribution, or a penalty inflected on an offender through judicial procedure, and severe, rough or disastrous treatment" (Webster's Ninth Collegiate Dictionary, 1987). The dual meanings of such terms (Foxx, 1996) lead to a type of ambiguity that can adversely affect the bidirectional communication that is meant to help decrease problem behaviors through the use of behavioral principles. As yet another example, the term "consequences" almost always has an unpleasant connotation among the general public.

As a discipline, behavior analysis shares with various fields (e.g., education, medicine) the goal of positively influencing people's quality of life (Bailey, 1991). However, in the pursuit of this goal, behavior analysts strive to be science-driven and evidence-based, which means the field has a deep grounding in technical concepts and vocabulary. Bailey argued that linguistic habits that trace back to the field's laboratory roots have adverse effects on the pursuit of 
promoting everyday well-being. Applied behavior analysts may mistakenly believe that in using technical language that they are bolstering the field's credibility as science-based. But this attention to increasing the credibility and focus of science may actually distract from recognizing the need to develop effective "marketing" strategies that acknowledge human values in language that individuals outside the field of ABA can easily understand. For instance, Bailey (1991) pointed out that applied behavior analysts, in mimicking the linguistic habits of behavior scientists, may refer to those they work with as "subjects" and discuss interventions using terms like "control," "manipulate," and "intervention." To individuals who are not familiar with the meaning of $\mathrm{ABA}$ terminology, these terms can sound unpleasant and coercive and are unlikely to recruit buy-in from clients seeking behavioral support. Bailey's (1991) central point may be summarized as follows: The tools of applied behavior analysis are intended to benefit all individuals, but not all individuals are likely to regard behavior analysts as the sort of people in whom they prefer to place their trust.

Consistent with these worries, several studies suggest that potential clients regard ABA services as less acceptable when they are described using jargon as when they are described using everyday language (e.g., Becirevic, Critchfield, \& Reed, 2016; Jarmolowicz et al., 2008; Witt, Moe, Gutkin, \& Andrews, 1984). Jarmolowicz et al. (2008) also found that paraprofessionals who were taught an intervention using jargon did a worse job of implementing it than did peers who were taught using plain English. These studies do not show why jargon is problematic but support the assumption that jargon has potential adverse effects on the "marketing" and dissemination of ABA. 


\section{Linguistic Diversity Challenges}

In evaluating the challenges of speaking pleasantly and clearly about applied behavior analysis, it is important to keep in mind that psychology as a discipline is a highly culture-bound mainstream European-American phenomenon (Hall, 2001). This insight has many implications, but in general it is deemed to be important for clinicians to develop an awareness of cultural differences and to adapt modes of therapy to respect and harness these differences (e.g., Bolling, 2002; Hall, 2001).

One domain of clear relevance concerns the native language(s) that clients speak. For example, the largest minority group in the United States is Latinx population. According to the Pew Research Center's (2013) National Survey of Latinos, 36\% are bilingual, 25\% mainly use English, and 30\% mainly use Spanish. Among those who speak English, 59\% are bilingual (Pew Research Center, 2013).

As ethnic and cultural diversity continues to increase in the United States, it is important to be able to translate the research and practices of ABA therapy in a culturally and linguistically sensitive manner. If, however, English-speaking clients exhibit difficulties understanding relevant theories and concepts related to $\mathrm{ABA}$, then it can be safe to assume that individuals with other native languages may have similar difficulties.

Although no actuarial statistics are available, casual observation suggests that most therapists trained in ABA are native English speakers. This implies a limited capacity to communicate with non-native English speakers. Research suggests that in the United States, Latinx children with ASD are under-identified or identified at a later age than children of English-speaking families (Zuckerman et al., 2013). This trend may well result from a shortage of Spanish-speaking or Bilingual ABA therapists and pediatricians, and likely results in Latinx 
children with ASD not receiving the early intervention services that researchers have shown are most effective (Reichow, 2012). As the number of Latinx children diagnosed with ASD and other developmental disorders continues to increase, it is important to be able to communicate the necessary information about interventions in Spanish as well as English.

Translating from one language to another can be a difficult skill to master, and in therapeutic situations, the stakes for interpreting information clearly are high. In medical situations, for example, English-speaking staff may need to rely on family members to help with interpreting. But this can be problematic, in part because neither the patient nor the ad hoc translators may be familiar with medical jargon. Large medical institutions and hospitals often use phone services to quickly provide consumers with help in several languages, but once again, those consumers may not understand the jargon that is used. Analogously, in the ABA community, the first systematic effort at addressing translation problems was undertaken by the Behavior Analyst Certification Board ${ }^{\circledR}(\mathrm{BACB})$, which produces glossaries of technical terms in several languages, including Spanish (https://www.bacb.com/wp-content/uploads/2017/09/ Spanish-English-ABA-Glossary.pdf). However, these glossaries say nothing about how consumers might actually understand or experience these terms (Critchfield \& Doepke, 2018).

\section{Word Emotion}

As mentioned previously, jargon could have at least two independent effects on listeners who are not familiar with the field of ABA: First, an individual may not understand (or may misunderstand) the meaning of jargon. Second, an individual may understand jargon terms, but in ways that are separate from their intended meaning. Moreover, such terms may evoke emotional reactions that are separate from explicit word meaning (Foxx, 1996). That is, the connotation of a word (i.e., the emotional association surrounding the word) may have an impact 
on the denotation of a word (i.e., the strict dictionary meaning; Jay \& Janschewitz, 2007). The present investigation focuses on the emotional effects that words have.

Recognizing that words provide triggers to various emotional states, researchers have developed methods of quantifying these states. Doing so has facilitated several lines of investigation aimed at understanding: (a) the impact that emotional responses to words have on processing and memory; (b) the way emotional responses to words affect subsequent behavior; (c) the way emotional responses to individual words contribute to the overall sentiments experienced through larger messages; and (d) the ways in which new words acquire emotional properties (Warriner, Kuperman, \& Brysbaert, 2013). For present purposes, however, the primary interest is simply in measuring emotional responses to words.

To date, the procedures of most word-emotion studies have been based on Bradley and Lang's (1999) Affective Norms for English Words (ANEW) and its various translated versions (e.g., Warriner et al., 2013). ANEW was developed to provide a set of normative emotional ratings for words in the English language (Bradley \& Lang, 1999). The goal of this research was to have a set of verbal materials that has been rated in terms of three dimensions of emotion: valence (ranging from pleasant to unpleasant), arousal (ranging from calm to excited), and dominance (ranging from dominant to submissive) (see Osgood, Suci, \& Tannenbaum, 1957; Russell \& Mehrabian, 1977). In the current investigation, I focused on both arousal and valence in Study 1 and valence in Study 2. Arousal was measured because it is related to Skinner's (1953) description of emotions as motivating operations that make some behaviors more or less reinforcing to engage in (Critchfield \& Doepke, 2018). Furthermore, Warriner and Kuperman (2015) suggested that arousal and valence interact to enhance each other to determine an overall emotional response to words. 
The original ANEW norms include ratings for 1,034 English words (Bradley \& Lang, 1999) that were obtained using Self-Assessment Manikins (SAM), a form of rating scale employing emotion-specific facial icons as response options instead of word anchors (see also Dodds et al., 2015). Many other studies have used more traditional word-anchored rating scales, and have produced results that correlate highly with the SAM ratings from ANEW (Warriner et al., 2013).

Word emotion-rating procedures operate similarly for SAM and traditional Likert-type scales. Raters are chosen for competence in the language under consideration, and are presented with words one at a time. They are asked to indicate how each word makes them feel, and are told to respond quickly and without deliberate thought in order to record their first gut-level reaction. Norms consist of the means of ratings made by many individuals (e.g., 1,827 valid responders in Warriner et al., 2013).

Although such procedures are relatively simple, they are given a measure of validity by research showing that when people experience words in context -- as part of a larger message -- a variety of reactions to the larger message are predictable from the ratings of the individual words in it. For example, mean valence predicts that words that generally make people feel a sense of happiness are easier to picture, concrete, familiar, and they are usually associated with low pain (Warriner et al., 2013). Similarly, words that provide positive emotions can help communicate persuasive messages. Mitchell, Brown, Morris-Villagran, \& Villagran (2001) explained that an important moderator of the effectiveness of persuasive messages is the emotion experienced by the receiver of the message. 


\section{Emotional Responses to ABA Jargon}

As previously discussed, it can be difficult to "market" ABA to clients in need of behavioral services due to the technical language used in behavioral treatments, and this may be due in part to emotional baggage carried by some of the words that function as ABA technical

terms. In order to assess the emotional responses individuals outside the field of ABA may have to behavioral jargon used frequently in behavioral treatment, Critchfield et al. (2017) selected words that behavior analysts use as technical terms and referenced them against normative word emotion data provided by Warriner et al. (2013) and Dodds et al. (2015). They also obtained normative word emotion data for words that are commonly used to discuss general science, clinical work, and behavioral assessment. As expected based on concerns about the "marketing problem," ABA terms tended to score as more unpleasant than other professional terms, and more unpleasant than English words generally (Critchfield et al., 2017). For example, ABA terms such as "punishment" were rated as more unpleasant than science terms such as “experiment." This area of research is helpful in identifying how emotional responses to behavioral jargon could interfere with treatment implementation and integrity.

Although most discussions of ABA's "marketing problem" have concentrated on English-language behavioral jargon, Critchfield and Doepke (2018) identified a need for crosslanguage and cross-cultural studies on the acceptance of ABA and the role that its peculiar technical vocabulary may play in the overall acceptability of the field. They used the same method as Critchfield et al. (2017), using ABA terms from published norms in English and five other languages. Critchfield and Doepke (2018) found some cross-language similarities: terms that were perceived as pleasant (unpleasant) in English were perceived similarly in Spanish, French, Portuguese, German, and Arabic. Critchfield and Doepke's study included only a small 
set of ABA terms because they examined published word-emotion corpora that included only those words that double as ABA terms. Critchfield and Doepke pointed out that a more thorough examination of the emotional properties of $\mathrm{ABA}$ terms in different languages will require collecting novel ratings rather than relying on previously published corpora. This is the general goal of the proposed investigation.

\section{The Current Study}

The goal of the current research was to evaluate whether word-emotion effects for ABA terminology that have been documented in English in the analysis of existing word corpora apply to perceptions of ABA jargon by English speakers and by bilingual speakers. Across two studies, I evaluated a large sample of ABA terms to examine similarities and differences in emotional responses to ABA terms in English and Spanish by bilingual speakers. Importantly, I collected novel emotion ratings for a larger set of ABA terms with respect to both valence and arousal. In Study 1, I examined responses to ABA terms and general psychological terms by English speakers (Chapter III). In Study 2, I examined responses to ABA terms and general psychological terms in English-Spanish bilinguals (Chapter IV). 


\section{CHAPTER III: STUDY 1}

Previous research has examined word-emotion ratings for ABA terms. The current study replicates and extends this work by (a) using a larger set of ABA terms (single words and compound terms) than previous studies (e.g., Critchfield \& Doepke, 2018), and (b) presenting these terms to participants to rate rather than using existing corpora. As noted in Chapter II, Critchfield and Doepke suggested that a more thorough examination of the emotional properties of ABA terms in different languages would require collecting novel ratings rather than relying on previously published corpora. Critchfield et al. (2017) plotted the ABA terms that exist in the language corpora (some of which have alternative meanings, such as elopement or extinction). In the present study, a context is established in which most of the terms are psychological or clinical in nature, whereas in Warriner et al. (2013), the context was a large set of general English words.

The specific research questions that I addressed in the first study are:

Research Question 1: How do mean emotional response ratings (valence) for ABA technical terms and general psychological terms made by participants compare to normative emotional response ratings (valence) for same-language words generally?

Research Question 2: How do mean emotional response ratings (valence and arousal) for ABA technical terms made by participants compare to normative emotional response ratings (valence and arousal) for the same terms for those available from the Warriner et al. (2013) corpus that were analyzed by Critchfield et al. (2017)? 
Research Question 3: How do emotional response ratings (valence and arousal) for ABA technical terms compare to those for a set of general psychological terms related to clinical practice but not to ABA specifically?

\section{Method}

\section{Participants}

Volunteers consisted of 237 volunteers that were recruited through mTURK; all were at least 18 years of age and self-identified as monolingual English speakers. Participation was restricted to individuals who reside in the United States. Those who completed the survey and responded to attention check questions correctly were paid $\$ 1.00$ for their participation. Each participant completed either the valence task or the arousal task.

A total of 123 volunteers completed the valence task. Eleven individuals were eliminated based on criteria set out by Warriner et al. (2013) that will be described in more detail in the Results section below. This left 112 participants, 71 of whom were male (63.4\%) and the majority of whom identified as being White/Caucasian $(n=86 ; 76.8 \%)$. Nine participants identified as Asian/Pacific Islander (8.0\%), six identified as Multi-Racial/Multi-Ethnic (5.4\%), four identified as Black/African American (3.6\%), and five identified as Hispanic/Latino (4.5\%). Two respondents preferred not to answer this question. Most participants had a Bachelor's Degree $(n=41 ; 36.6 \%)$ or Some College $(n=36,63.4 \%)$. The average age was 37.06 years ( $S D$ $=11.13)$. The majority did not have children $(n=72,64.3 \%)$. Three participants $(2.7 \%)$ reported having at least one family member who had received behavioral (ABA) services in the past, and two (1.8\%) reported having at least one family member who was receiving behavioral (ABA) services at the time the survey was completed. 
A total of 114 volunteers completed the arousal task. Thirty-eight individuals were eliminated from this rating task based on Warriner et al.'s criterion described below. This left 76 participants, approximately half of whom were male $(n=41 ; 53.9 \%)$ and the majority of whom identified as White/Caucasian $(n=66,86.8 \%)$. Three participants identified as Asian/Pacific Islander (3.9\%), three identified as Hispanic/Latino (3.9\%), two identified as Black/African American (2.6\%), and two identified as Multi-Racial/Multi-Ethnic (2.6\%). Most had completed High School $(n=25 ; 32.9 \%)$ and Some College $(n=13 ; 17.1 \%)$. The average age was $37.71(S D$ $=11.10)$. The majority of participants did not have children $(n=51 ; 67.1 \%)$. Three participants (3.9\%). reported having at least one family member who had received behavioral (ABA) services in the past and two participants $(2.6 \%)$ reported having had at least one family member who was receiving behavioral (ABA) services at the time the survey was completed.

\section{Measures}

Word lists. The 92 words/terms employed in the study were classified into one of four categories: (a) calibrator words $(n=9)$, (b) general psychological terms $(n=33)$, (c) ABA technical terms $(n=36)$, and $(d)$ control words $(n=14)$. All calibrator and control words were previously normed for emotional valence and arousal (Warriner et al., 2013), as were 26 of the general psychology terms and 13 of the ABA technical terms. The nine calibrator words were

presented in a fixed sequence at the beginning of the survey. The calibrator words included terms such as mechanic, accomplishment, and terrorism for the valence dimension and party, cat, and meditation for the arousal dimensions. The calibrator words were chosen separately for each of the two dimensions with the goal of providing participants practice with a large range of stimuli before beginning the task and were selected from norming samples in English (Warriner et al., 
2013). The calibrator words presented the participants with an opportunity to use the whole rating scale, as words were selected with norms that were high, middle, and low.

Thirty-three of the words were classified as general psychological terms used in clinical practice and included words such as disorder, confidentiality, and addiction. Word emotion ratings for 26 of these terms were identified from Warriner et al. (2013). Various other terms (or short phrases) such as learned helplessness, substance abuse, and play therapy do not have established norms. For the applied behavior analysis technical terms, 36 words or short phrases were used. This list included the 13 terms used in the Critchfield and Doepke (2018) study for which word-emotion rating norms were available and several terms consisting of short phrases (e.g., preference assessment) for which no established norms were available, with the latter selected from the BACB (2014) Spanish-English glossary.

Control words were included in order to serve as additional attention checks throughout the survey. Control words included terms such as jail, joke, and sunshine for the valence list and dangerous, emergency, and assault for the arousal list. These words were selected from the norming studies by Warriner et al. (2013). The control words were interspersed randomly throughout the list of $\mathrm{ABA}$ and general psychological terms to ensure respondents were attending to the task. That is, if participants did not make ratings similar to the established norms across this set of words (e.g., if "rampage" was rated as evoking positive emotions or "thrill" was rated as calming) then those participants were eliminated from the final sample for data analysis purposes (described in more detail below).

Rating scales. As in the norming studies by Warriner et al. (2013), participants worked independently and were asked to evaluate terms, presented visually one at a time, on one of the two emotional dimensions of interest. The anchors ranged from negative emotion to positive 
emotion. Participants who completed the valence task rated the terms on a scale of $1=$

"Unhappy" to $9=$ "Happy." Those who completed the arousal task rated the terms on a scale of $1=$ "Calm" to $9=$ "Excited."

Language use. Five items from the Acculturation Scale for Hispanics (Marin, Sabogal, Marin, Otero-Sabogal, \& Perez-Stable, 1987) were used to confirm that respondents were monolingual English speakers. This scale includes a factor for "Language Use and Ethnic Loyalty," which includes five items that assess preference for using English versus Spanish for reading and speaking as an adult, language use in childhood and at home, language use when interacting with friends, and typical language used for thinking (see Appendix A). There are five available responses to choose from: "Only Spanish," "Spanish better than English," "Both Equally," "English better than Spanish," and "Only English."

\section{Procedure}

Recruitment platform. Participants were recruited through Amazon Mechanical Turk (mTurk), which has become a popular method for crowdsourcing recruitment and data collection worldwide (Harms \& DeSimone, 2015). Researchers develop "Human Intelligence Tasks" (HITs), which can include surveys, experiments, and/or coding tasks, and pay a fee to volunteers for completing them (Keith, Tay, \& Harms, 2017). This method has created the opportunity for researchers to collect data at a reduced cost and with samples showing greater diversity with respect to education and age than the typical samples of college students used in psychological research (Keith et al., 2017).

Following mTurk conventions, the current study was announced in the system via a onesentence study description accompanied by a description of inclusion/exclusion criteria and the compensation amount being offered for completion (\$1.00). To participate in the current study, 
respondents were required to have completed at least 25 previous HITs and to have earned a HIT Approval Rate of at least $80 \%$, meaning they had successfully completed at least $80 \%$ of the previous HITs for which they had volunteered.

Data collection platform. Individuals interested in participating in the study were directed to a link into the Qualtrics® online survey platform. Although data can be collected within MTurk, for present purposes an outside platform was employed to protect participant confidentiality, because within MTurk it is theoretically possible to determine volunteer identities via the Amazon online accounts through which they are paid. Within Qualtrics, no identifying information was recorded, leaving the data set anonymous.

Within Qualtrics, volunteers were first presented with an Informed Consent Screen, which contained the IRB-approved consent agreement and check boxes for either granting or declining permission to participate. Volunteers who agreed to take part in the study then clicked a button to produce the rest of the survey. Otherwise they clicked a decline button and were prompted to exit from the Qualtrics site.

Those who agreed to participate were randomly assigned to complete either the valence rating task or the arousal rating task. Prior to beginning the ratings participants were presented with written instructions indicating that the terms would be presented and rated one at a time and describing the rating scale. For valence ratings, the anchors ranged from negative emotion to positive emotion on a scale of $1=$ "Unhappy" to $9=$ "Happy." Following the procedure of Warriner et al. (2013), the current study's instructions explained that "Unhappy” was equivalent to "annoyed, unsatisfied, melancholic, despaired, or bored," and "Happy" was equivalent to “pleased, satisfied, contented, hopeful” (p. 1193; see Appendix B). For arousal ratings, the anchors ranged from $1=$ "Calm" to $9=$ "Excited." Following the procedure of Warriner et al. 
(2013), the current study's instructions explained that "Calm" was equivalent to "relaxed, sluggish, dull, sleepy or unaroused" and "Excited" was equivalent to "stimulated, frenzied, jittery, wide awake, or aroused."

The data collection session started with nine calibrator words and one attention check question that asked participants to select a specific number. Attention checks were used in order to ensure that each participant was attending and understood the instructions. Next, a random list of ABA terms, general psychological terms, and control words were presented to each participant. Terms were randomized for each participant. A total of four attention checks were randomly presented throughout the main task. After participants completed the word-rating task, they provided demographic information (see Appendix C) and completed the Language Use subscale of the Acculturation Scale for Hispanics. After the survey was completed, a final screen thanked the participant and provided a validation code and instructions to return to the MTurk page to enter the code to receive payment. This screen also included the researchers' contact information.

\section{Results}

\section{Data Trimming}

Several steps were employed to assure that only high-quality data were analyzed. First, the initial set of nine calibrator words from Warriner et al. (2013) were used to identify individuals who did not use the rating scale with fidelity (e.g., rating terrorism as happy, or attack as calm). Next, for each participant, a simple correlation was calculated between normative ratings from Warriner et al. and those provided by the participant. My original plan was to eliminate participants with correlation coefficients less than +0.35 . After calculating simple correlations and flagging 111 participants (19/123 from the valence group and 92/114 
from the arousal group) who produced a correlation of less than +0.35 , I decided to use the same criterion as Warriner et al. (2013), and exclude any participant with a correlation of less than +0.10 .

Using the +.10 cutoff, 11 participants $(9 \%)$ were eliminated from the valence condition (instead of 15\%), and 38 participants (33\%) were eliminated from the arousal condition (instead of $80 \%$ ). Because the correlations were so unusual for such a large number of participants in the arousal condition using the original criterion, the correlation coefficients for control words, calibrator words, ABA terms, and General Psychological terms were examined separately. For many participants in the arousal condition, there were very small, or even negative, correlation coefficients for the ABA and General Psychological terms, but significant positive correlations for the calibrator and control words. This pattern was not evident for the valence condition and will be discussed in more detail in the Discussion section below.

\section{Research Questions}

Research Question 1 addresses how the emotional valence ratings for ABA technical terms and General Psychological terms in the current study compare to normative emotional valence ratings for same-language words generally. Table D-1 shows the percentile bins derived from Warriner et al.'s corpus of almost 14,000 words, the range of valence ratings that fell in each of the 10 deciles, and the frequency of ABA terms and General Psychological terms that fell into each bin. If ABA and General Psychological terms are distributed the same way as same-language words, generally, we would expect an approximately equal number of words in each of the 10 decile bins (i.e., approximately 3.6 words per bin for the set of $36 \mathrm{ABA}$ terms). ABA terms tended to be rated as slightly more unpleasant than same-language words, with $65 \%$ falling below the $50^{\text {th }}$ percentile. Only one of the ABA terms out of 36 fell in the $91-100^{\text {th }}$ 
percentile bin (the term positive reinforcement) but five of the 36 terms fell in the $0-10^{\text {th }}$ percentile bin. The 5th column of Tables D-2 and D-3 shows the decile bin corresponding to each of the ABA and General Psychological terms.

When comparing General Psychological terms to normative emotional ratings for samelanguage words generally, these terms were rated as slightly more unpleasant than samelanguage-words generally, with $58 \%$ falling below the $50^{\text {th }}$ percentile. Additionally, more words than would be expected based on a uniform distribution were in the extreme deciles. For example, five out of the 33 General Psychological terms fell in the $91-100^{\text {th }}$ percentile bin and 13 out of the 33 terms fell in the $0-10^{\text {th }}$ percentile bin (i.e., almost $40 \%$ of this set of terms were in the bin corresponding to the lowest possible "unhappy" ratings).

Research Question 2 addresses how the mean emotional response ratings (valence and arousal) for $\mathrm{ABA}$ technical terms compare to the normative emotional response ratings (valence and arousal) for the same terms in the Warriner et al. (2013) corpus that were analyzed by Critchfield et al. (2017). To answer the second research question, the mean and standard deviation of emotional ratings for each term and for each emotion dimension were calculated. Table D-2 presents the means and standard deviations for all ABA terms used in the current study with the 13 words used by Critchfield et al. from the Warriner et al. corpus designated with bold font. For this research question, the focus is on the 13 words used by Critchfield et al. that were also used in the current study.

Based on the results summarized in Table D-2, I assigned terms to four categories based on high/low valence $x$ high/low arousal. Following Critchfield et al. (2017), the four categories were labeled as follows: Blandly Pleasant (Valence $M=5-9$ and Arousal $M=1-5$ ), Rousingly Pleasant (Valence $M=5-9$ and Arousal $M=5-9$ ), Blandly Unpleasant (Valence $M=1-5$ ) and 
Arousal $M=1-5$ ), and Rousingly Unpleasant (Valence $M=1-5$ and Arousal $M=5-9$ ).

Critchfield et al. (2017) found that of the 13 ABA terms selected from the Warriner et al. corpus, seven fell into the "Blandly Pleasant" quadrant, but only four of the words in the current study did so. Only one of the ABA terms selected by Critchfield et al. fell into the "Rousingly Pleasant" quadrant, whereas two of the terms in the current study were "Rousingly Pleasant." The "Blandly Unpleasant" quadrant had the fewest terms, with one in the Critchfield study and one in the current study. Lastly, four of the terms selected from the Warriner et al. corpus were classified as "Rousingly Unpleasant" but six of the terms in the current study were classified as “Rousingly Unpleasant" (see Figure 1).

\begin{tabular}{|c|c|c|c|}
\hline \multicolumn{2}{|c|}{$\begin{array}{c}\text { Blandly Pleasant } \\
\text { (high valence/low arousal) }\end{array}$} & \multicolumn{2}{c|}{$\begin{array}{c}\text { Rousingly Pleasant } \\
\text { (high valence/high arousal) }\end{array}$} \\
\hline Warriner et al. & Current Study & Warriner et al. & Current Study \\
\hline $\begin{array}{c}\text { Function } \\
\text { Escape }\end{array}$ & Function & Stimulus & Stimulus \\
Response & Escape & & \\
Behavior & Response & \\
Reinforce & Behavior & & \\
Contingency & & & \\
Chain & & & \\
\hline \multicolumn{2}{|c|}{ Blandly Unpleasant } & & Rousingly Unpleasant \\
(low valence/low arousal) & Current Study & Warriner et al. & Current Study \\
\hline Warriner et al. & Contingency & Extinction & Extinction \\
\hline Consequence & & Deprivation & Deprivation \\
& & Punishment & Punishment \\
& & Discrimination & Discrimination \\
& & & Chain \\
& & & Consequence \\
\hline
\end{tabular}

Figure 1 Thirteen ABA words with established norms from the Warriner et al. (2013) corpus that were selected for analysis by Critchfield et al. (2017) and rated in the current study and how they were classified. Words that were classified in different categories across the two studies are indicated with italics. 
The same procedure was followed for the General Psychological terms (see Table D-3 for means and standard deviations). Of the 26 words for which there are norms from the Warriner et al. (2017) study, eight terms fell in to the "Blandly Pleasant" category, whereas 10 terms from the current data set were categorized as Blandly Pleasant. Nine terms fell in to the "Rousingly Pleasant" category for Warriner et al.'s data, whereas five terms in the current study were classified as "Rousingly Pleasant." Two of the selected terms were "Blandly Unpleasant" for Warriner et al.'s data, but three terms fell in this quadrant in the current study. Finally, seven of the selected terms were classified as "Rousingly Unpleasant" for Warriner et al.'s data, whereas eight were classified as "Rousingly Unpleasant" in the current data set (see Figure 2).

\begin{tabular}{|c|c|c|c|}
\hline \multicolumn{2}{|c|}{$\begin{array}{c}\text { Blandly Pleasant } \\
\text { (high valence/low arousal) }\end{array}$} & \multicolumn{2}{|c|}{$\begin{array}{c}\text { Rousingly Pleasant } \\
\text { (high valence/high arousal) }\end{array}$} \\
\hline Warriner et al. & Current Study & Warriner et al. & Current Study \\
\hline $\begin{array}{l}\text { Empathy } \\
\text { Plan } \\
\text { Feeling } \\
\text { Treatment } \\
\text { Therapy } \\
\text { Client } \\
\text { Obedience } \\
\text { Counseling }\end{array}$ & $\begin{array}{c}\text { Empathy } \\
\text { Plan } \\
\text { Feeling } \\
\text { Treatment } \\
\text { Therapy } \\
\text { Client } \\
\text { Confidentiality } \\
\text { Referral } \\
\text { Adjustment } \\
\text { Mood }\end{array}$ & $\begin{array}{c}\text { Reward } \\
\text { Praise } \\
\text { Motivation } \\
\text { Incentive } \\
\text { Emotion } \\
\text { Confidentiality } \\
\text { Referral } \\
\text { Adjustment } \\
\text { Mood }\end{array}$ & $\begin{array}{c}\text { Reward } \\
\text { Praise } \\
\text { Motivation } \\
\text { Incentive } \\
\text { Emotion }\end{array}$ \\
\hline \multicolumn{2}{|c|}{$\begin{array}{c}\text { Blandly Unpleasant } \\
\text { (low valence/low arousal) }\end{array}$} & \multicolumn{2}{|c|}{$\begin{array}{c}\text { Rousingly Unpleasant } \\
\text { (low valence/high arousal) }\end{array}$} \\
\hline Warriner et al. & Current Study & Warriner et al. & Current Study \\
\hline $\begin{array}{c}\text { Penalty } \\
\text { Addiction }\end{array}$ & $\begin{array}{l}\text { Depression } \\
\text { Counseling } \\
\text { Obedience }\end{array}$ & $\begin{array}{c}\text { Delusion } \\
\text { Denial } \\
\text { Disorder } \\
\text { Tantrum } \\
\text { Prejudice } \\
\text { Stress } \\
\text { Depression }\end{array}$ & $\begin{array}{c}\text { Delusion } \\
\text { Denial } \\
\text { Disorder } \\
\text { Tantrum } \\
\text { Prejudice } \\
\text { Stress } \\
\text { Penalty } \\
\text { Addiction } \\
\end{array}$ \\
\hline
\end{tabular}

Figure 2 General psychological terms $(n=26)$ with established norms from the Warriner et al. (2013) corpus and the current study and how they were classified. Words that were classified in different categories across the two studies are indicated with italics. 
Research Question 3 addresses how emotional response ratings (valence and arousal) for the 36 ABA technical terms compare to the 33 General Psychological terms. Critchfield et al. used a valence-arousal scatterplot to classify terms from the Warriner et al. corpus. As noted in Research Question 2, in the current data set the ABA terms and the General Psychological terms were each categorized into one of the four categories described above (high-valence/low-arousal; high-valence/high-arousal; low-valence/low-arousal; or low-valence/high-arousal). The ABA terms that were classified into each of the four categories are presented in Figure 3. The General Psychological terms are presented in Figure 4.

\begin{tabular}{|c|c|}
\hline $\begin{array}{c}\text { Blandly Pleasant } \\
\text { (high valence/low arousal) }\end{array}$ & $\begin{array}{c}\text { Rousingly Pleasant } \\
\text { (high valence/high arousal) }\end{array}$ \\
\hline $\begin{array}{l}\text { Function } \\
\text { Preference Assessment } \\
\text { Satiation } \\
\text { Shaping } \\
\text { Response } \\
\text { Behavior }\end{array}$ & $\begin{array}{l}\text { Positive Reinforcement } \\
\text { Escape } \\
\text { Reinforce } \\
\text { Elopement } \\
\text { Stimulus } \\
\text { Motivating Operation }\end{array}$ \\
\hline $\begin{array}{c}\text { Blandly Unpleasant } \\
\text { (low valence/low arousal) }\end{array}$ & $\begin{array}{c}\text { Rousingly Unpleasant } \\
\text { (low valence/high arousal) }\end{array}$ \\
\hline $\begin{array}{l}\text { Timeout } \\
\text { Establishing Operation } \\
\text { Operational Definition } \\
\text { Token Economy } \\
\text { Brief Functional Analysis } \\
\text { Antecedent } \\
\text { Target Behavior } \\
\text { Task Analysis } \\
\text { Generalization } \\
\text { Differential Reinforcement } \\
\text { Reinforcement Schedule } \\
\text { Contingency }\end{array}$ & $\begin{array}{l}\text { Discrimination } \\
\text { Punishment } \\
\text { Deprivation } \\
\text { Chain } \\
\text { Consequence } \\
\text { Extinction } \\
\text { Early Intensive Behavioral Intervention } \\
\text { Delayed Reinforcement } \\
\text { Incompatible Behavior } \\
\text { Negative Reinforcement } \\
\text { Stereotypy }\end{array}$ \\
\hline
\end{tabular}

Figure $3 \mathrm{ABA}$ terms $(n=36)$ categorized by high and low valence and high and low arousal assigned to each of the four categories of the valence-arousal scatterplot developed by Critchfield et al. (2017). 


\begin{tabular}{|c|c|}
\hline $\begin{array}{c}\text { Blandly Pleasant } \\
\text { (high valence/low arousal) }\end{array}$ & $\begin{array}{c}\text { Rousingly Pleasant } \\
\text { (high valence/low arousal) }\end{array}$ \\
\hline $\begin{array}{l}\text { Client } \\
\text { Therapy } \\
\text { Treatment } \\
\text { Mood } \\
\text { Feeling } \\
\text { Adjustment } \\
\text { Confidentiality } \\
\text { Empathy } \\
\text { Referral } \\
\text { Plan }\end{array}$ & $\begin{array}{l}\text { Praise } \\
\text { Emotion } \\
\text { Motivation } \\
\text { Incentive } \\
\text { Reward }\end{array}$ \\
\hline $\begin{array}{c}\text { Blandly Unpleasant } \\
\text { (low valence/low arousal) }\end{array}$ & $\begin{array}{c}\text { Rousingly Unpleasant } \\
\text { (low arousal/high valence) }\end{array}$ \\
\hline $\begin{array}{l}\text { Depression } \\
\text { Play Therapy } \\
\text { Counseling } \\
\text { Obedience }\end{array}$ & $\begin{array}{l}\text { Disorder } \\
\text { Delusion } \\
\text { Denial } \\
\text { Stress } \\
\text { Addiction } \\
\text { Chronic Stress } \\
\text { Risk Factors } \\
\text { Behavior Modification } \\
\text { Prejudice } \\
\text { Learned Helplessness } \\
\text { Substance Abuse } \\
\text { Anxiety } \\
\text { Penalty } \\
\text { Tantrum }\end{array}$ \\
\hline
\end{tabular}

Figure 4 General Psychological terms $(n=33)$ categorized by high and low valence and high and low arousal assigned to each of the four categories of the valence-arousal scatterplot developed by Critchfield et al. (2017).

The percentages of each type of term (ABA, general psychological terms) in each of the four categories were analyzed with a 2 x 4 Chi-square test of association (see Figure 5). An association was found between variables, $\chi^{2}(3, N=68)=16.08, p<.001$. Thus, in comparing ABA terms with General Psychological terms, there were differences in the proportion of each type that were assigned to the four categories. As seen in Figure 5, there were more ABA terms classified as "blandly unpleasant" relative to the General Psychological terms. Based on the 
findings of Critchfield et al. (2017), it was expected that for the valence dimension (i.e., pleasant vs. unpleasant) ABA terms would be rated as more unpleasant than General Psychological terms. A $2 \times 2$ Chi-square test of association was used to examine the proportion of ABA and General Psychological terms classified as pleasant or unpleasant. For the ABA terms, $66 \%$ were unpleasant, while for the General Psychological terms 54\% were unpleasant, $\chi^{2}(1, N=68)=$ $3.00, p=.08$. Thus, in the current sample, participants found the two types of jargon equally unpleasant.

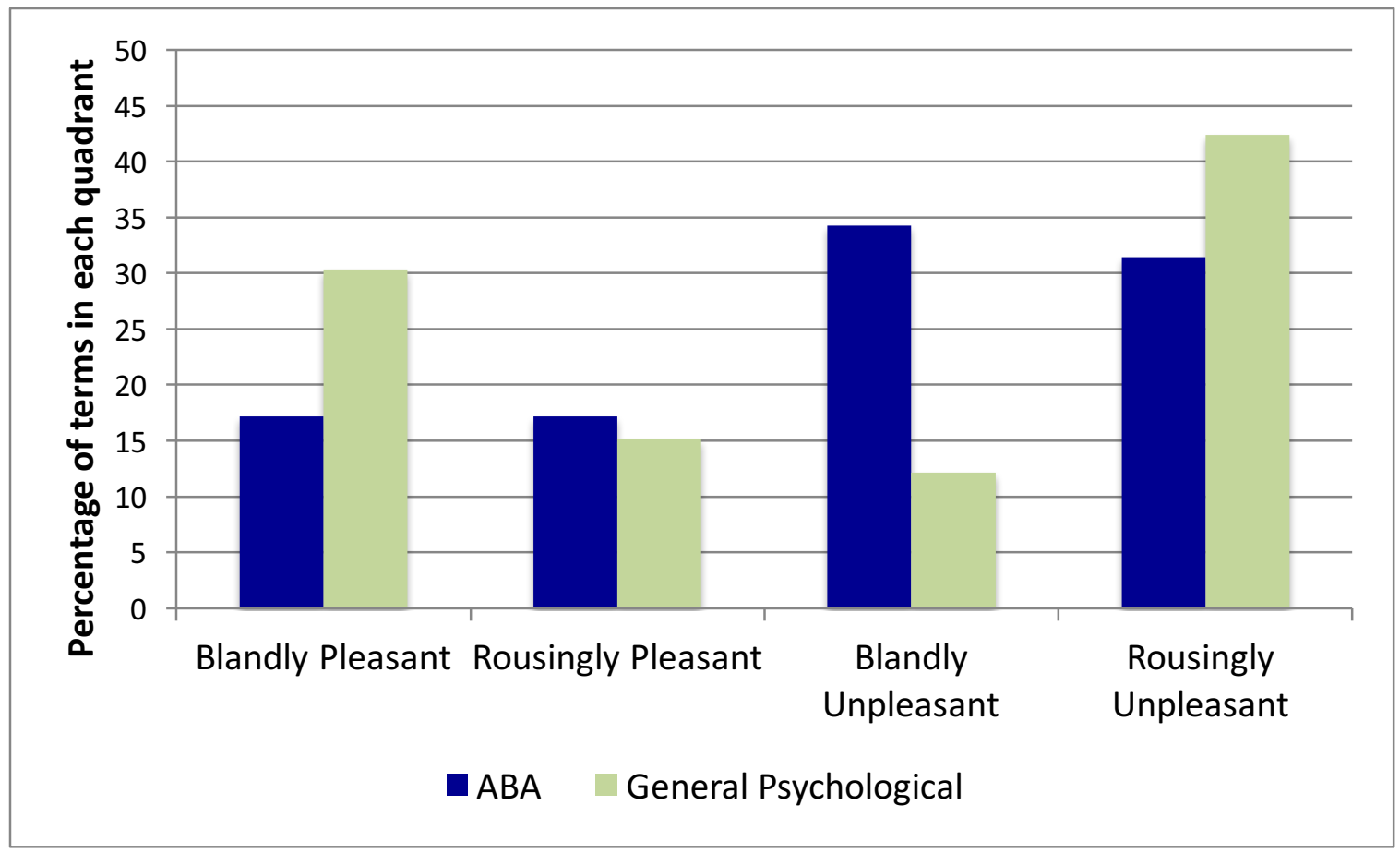

Figure 5 Percentages of ABA technical terms and General Psychological terms that fall into each of the four quadrants of a valence-arousal scatterplot. 
The means and standard deviations for the control and the calibrator words for valence and arousal are presented in Tables D-4 through D-7. These tables also include corresponding norms from the Warriner et al. (2013) corpus. These data are presented for the sake of completeness, but as can be seen the means from the current study are very similar to those found by Warriner et al. (2013), suggesting participants in the current study were appropriately calibrated.

\section{Study 1 Discussion}

The central focus of Study 1 was to replicate and extend previous work on word emotion by Critchfield et al. (2017) by using a larger set of ABA terms (single words and compound terms) and presenting these terms to participants to rate rather than using existing word-emotion corpora. Critchfield et al. (2017) selected 39 words related specifically to ABA from Warriner et al.'s word corpus along with 35 clinical terms used by ABA practitioners but which are also used in general clinical practice. They found that ABA terms were rated as more unpleasant than the clinical terms. In the current study, a set of General Psychological terms was selected for participants to rate in addition to ABA terms in order to further explore if the effects found by Critchfield et al. are unique to ABA jargon. In the current study, General Psychological terms were rated as unpleasant as ABA terms. It is important to note that only three of the general clinical terms used by Critchfield et al. were used in the current study. The ability to select a variety of words and compound terms to be presented for novel ratings, rather than using existing norms, allowed for a novel comparison of emotion ratings between a wider range of ABA and General Psychological terms. For instance, rather than using existing terms such as "intensive," "problem," and "severe" that may have multiple interpretations, the current study used terms 
found in psychology textbooks and terms commonly used in therapy such as "substance abuse," "risk factors," and "learned helplessness."

Consistent with previous research, most individuals found ABA jargon unpleasant. It is important, however, to note that this effect does not seem to be quite as strong as Critchfield et al. reported based on word emotion ratings from the Warriner et al. corpus. In other words, presenting ABA terms and General Psychological terms to participants to rate rather than using the existing norms produced a different pattern of results. Critchfield et al. (2017) examined Warriner et al.'s emotional ratings to 34 behavioral assessment words (individual words related to measuring behavior and detecting clinical effects) and 35 general clinical terms (words that behavior analysts use but which are not unique to $\mathrm{ABA}$ ). The terms used in the current study were generated with the goal of further exploring emotional response ratings to specific ABA and General Psychological terms.

Each participant in Warriner et al. (2013) rated a set of approximately 350 individual words from a larger set of nearly 14,000 English words. In the current study, participants rated a total of 94 terms. About $75 \%$ of the items were either ABA technical terms or General Psychological terms. Although it was not explicitly stated in the instructions that the terms would be largely focused on behavioral or psychological terms, there is a high likelihood that participants noticed the pattern. Almost $70 \%$ of the participants in both conditions (valence and arousal) had taken one or more psychology courses. If participants did become aware of this pattern, it would be difficult to confidently state that the current study is completely "contextfree." Any differences in ratings for selected terms between the current study and the Warriner et al. norms may therefore be due to the implicit psychological context provided by the overall set of terms. This pattern of findings can be explained by the spreading activation mechanism 
proposed by Anderson (1983). Anderson proposes that concepts in memory are stored in networks. If one concept is remembered or activated, that activation is quickly spread within one's cognitive network such that other related concepts also become remembered at various levels of activations. For example, when asked to think about the word "lion," an individual's cognitive network will activate related concepts depending on which schema or network becomes most active. For example, it is possible that "lion" activates concepts such as "tigers" and "cheetahs" (i.e., those related to big cats), or "zebras" and "elephants" (i.e., related to African animals). Thus, there is an immediate activation based on previous memories and experiences that are stored in cognitive networks. In this case, a psychological term such as "therapist" or "depression" may automatically activate an individual's conceptual network related to psychology and the individual might automatically think of related words. If so, ABA and General Psychology terms that have more than one connotation, such as "discrimination" or "elopement" would then be interpreted with their psychology connotations rather than the connotation from the vernacular. When making emotional response ratings to randomly presented words from the English language, as was the case in Warriner et al., participants may have encountered words that have both a psychological meaning and a more everyday meaning. Thus, in this "context-free" setting, it is possible they may have been making emotional responses to the most dominant meaning of that specific word, which may not be the psychological meaning.

The results of the cross-study comparison, focused on the 13 ABA terms Critchfield selected from the Warriner et al. (2013) corpus and the 26 General Psychological words that have Warriner et al. (2013) norms, show that individuals find General Psychological terms as unpleasant as ABA terms. After classifying the ABA terms into the four categories (Blandly 
Pleasant, Rousingly Unpleasant, Blandly Unpleasant, and Rousingly Unpleasant) and comparing them to Critchfield et al.'s classifications of ABA terms, approximately $40 \%$ of the words switched from the Bland to Rousing categories (i.e., changed in the arousal dimension) in the current study. There were two exceptions where a word was rated differently on the valence dimension: "chain" and "consequence." As previously stated, the context provided in the word rating task may have contributed to the different pattern of results. For instance, the word "consequence" may be experienced as a pleasant term within the field of psychology but may have a less pleasant connotation in the vernacular. Similarly, out of context the word "chain" may have a neutral connotation (e.g., "bike chain" or "chain mail") or positive connotation (e.g., "necklace") in the vernacular, depending on which other concepts are activated. In a context that supports a psychology interpretation, this jargon term seems to have a less pleasant connotation.

As discussed in Chapter II, arousal was measured in Study 1 because it is related to Skinner's (1953) description of emotions as motivating operations that make some behaviors more or less reinforcing to engage in (Critchfield \& Doepke, 2018). Additionally, Warriner and Kuperman (2015) suggested that arousal and valence interact to enhance each other to determine an overall emotional response to words. After analyzing the data in the current study, however, it was clear that the correlations were "aberrant" for a large number of participants in the arousal condition (i.e., $80 \%$ of the sample would have been eliminated using the original planned cutoff criterion). In the arousal condition, there were many non-significant and even negative correlations between the participant ratings and established norms (Warriner et al., 2013) for the ABA and General Psychological terms. At the same time, there were significant positive correlations for these same participants for the calibrator and control words. Such results suggest that it may have been difficult to decipher and apply the "Calm" to "Excited" anchors and apply 
them to the ABA and General Psychological terms. Far fewer participants in the valence condition were eliminated, thus it was easier to apply the "Unhappy" to "Happy" anchors to the entire set of words. Based on the aforementioned results, the planned arousal ratings were not included in the methodology for Study 2 because these ratings were potentially neither reliable nor valid in Study 1. 


\section{CHAPTER IV: STUDY 2}

\section{Bilingualism and Word Emotion}

Much of the research that has been conducted on emotional responses to specific words has been conducted with monolingual individuals; however, less is known about how bilinguals make emotional response ratings to individual words or terms. Previous research on emotional expression in bilingual individuals has shown that language plays a large role in emotional expression (Marian \& Kaushanskaya, 2008). More specifically, bilingual individuals express emotions in a different way depending on the language they are using at the time (Marian \& Kaushanskaya, 2008). For example, Anooshian and Hertel (1994) suggested that people use more emotionally laden terms in their native language than their second language, and that the native language is what bilingual individuals prefer to use when expressing positive emotions. According to Bond and Lai (1986) an individual's second language allows for more distance from an emotional experience. Marian and Kaushanskaya (2008) suggested that this may be due to the idea that individuals need to process a second language more deeply, which allows individuals to build tolerance to the emotions evoked by unpleasant words and encourage further processing. Such findings are important to consider when working to develop an emotional connection with bilingual individuals in clinical settings.

There are, however, multiple variables that need to be accounted for in the aforementioned findings. For instance, previous research on language processing in bilingual individuals has suggested that cognitive variables such as a bilingual person's language proficiency can play a role in overall linguistic processing (Marian \& Kaushanskaya, 2008). Blumenfield and Marian (2007) demonstrated that higher proficiency in a language can lead to 
more cognitive activation during language processing. Marian and Kaushanskaya (2008) suggested that rather than proficiency, an important variable to consider is emotional attachment to the language. That is, although individuals may show competence in a specific language (i.e., proficiency), emotional attachment to a language (i.e., preference) may be an indicator of attachment to the meaning of the language and its associations (Marian \& Kaushanskaya, 2008). Overall, it may be said that although there is a wide agreement that word emotion is an important component of bilingualism, the existing literature provides no clear basis for predicting specific word emotion effects in people who speak multiple languages.

Clinical case studies support the possible importance of word emotion in clinical work with bilingual clients. Specifically, Pavlenko (2008) illustrated how emotional attachment to a language might be important. These case studies showed that individuals who began therapy in their second language (English), after refusing to use their native language when given the option, but then had to switch to their first language experienced either breakthrough or emotional outbursts when using their native language (Aragno and Shlachet, 1996; Javier, 1995; Movahedi, 1996). Pavlenko (2008) suggested that this pattern of behavior might be due to the memories that come with words expressed in the native language. Such results encourage further research in the area of word emotionality in bilinguals in order to enhance communication between therapist and clients.

My second study focuses on bilingual (English and Spanish) speakers because past research suggests that even within the same individual emotional responses are not necessarily equivalent for "equivalent" translated terms (e.g., Pavlenko, 2008). I asked individuals to rate terms in both English and Spanish, and I compared these reactions, taking into account each rater's level of acculturation, which roughly means degree of comfort in each language. The 
focus of Study 2 is to address differences and/or similarities in word emotion ratings made by bilingual speakers and to explore whether language acculturation and language preference for expressing emotion has an influence on these emotion ratings. Based on the findings described in Chapter III regarding lack of consistency in arousal ratings, participants were not asked to complete an arousal rating for the ABA and General Psychological terms in Study 2. The current study focuses only on emotional ratings of valence.

The specific research questions that addressed in the second study are:

Research Question 4: Are valence ratings for English and Spanish terms positively correlated when rated by bilingual speakers? Are there specific terms where there are notable differences between bilingual participants' ratings in English and Spanish?

Research Question 5: Are the emotional response ratings made by bilingual speakers to the same terms in English and Spanish related to their preferred language for communication (English, Spanish, or both equally)?

Research Question 6: Are the emotional response ratings made by bilingual speakers to the same terms in English and Spanish related to their preferred language for expressing negative emotions?

Research Question 7: Are the emotional response ratings made by bilingual speakers to the same terms in English and Spanish related to their preferred language for positive emotions?

\section{Method}

\section{Participants}

A total of 141 volunteers who were at least 18 years of age were recruited through mTurk. Volunteers who completed the survey and responded to attention check questions 
correctly were paid \$1.25 for their participation. Volunteers were bilingual English and Spanish speakers, and they completed the valence task in both English and Spanish. Participation was restricted to individuals who reside in the United States and Mexico.

Of the 141 volunteers who completed the survey, 15 were eliminated for one of the following reasons: (a) responses consisted of clear repeating patterns (e.g., 4, 5, 6, 4, 5, 6, 4, 5, $6 \ldots$ ); (b) they did not use the whole scale (e.g., 7, 7, 7, 7...); or (c) there was a consistently large difference (i.e., 4 to 5 points) between ratings for the same term in English and Spanish when rating calibrator and control words that have established norms.

Of the remaining 126 participants, 65 were male (48.4\%) and 61 were female $(51.6 \%)$. The majority of participants identified as being Hispanic/Latino $(n=65,51.6 \%), 51$ participants identified as White/Caucasian (40.5\%), five participants identified as Multi-Racial/Multi-Ethnic (4.0\%), three participants Black/African American (2.4\%), one participant identified as Native American (.8\%), and another participant identified as Asian/Pacific Islander (.8\%). Most participants had a Bachelor's Degree $(n=59,46.8 \%)$ or Some College $(n=21,16.7 \%)$. The average age of the participants was 33.53 years $(S D=9.87)$. The majority of participants did not have children $(n=79,62.7 \%)$. Twenty-seven participants $(21.4 \%)$ reported having at least one family member who had received behavioral (ABA) services in the past. Seven participants $(5.6 \%)$ reported having at least one family member who is presently receiving behavioral (ABA) services.

\section{Measures}

Demographic Survey. Three additional questions were added to the demographics survey used in Study 2. In order to assess language preference, participants were asked to decide which language they would prefer receiving new information from various sources that use 
technical language (e.g., teachers, doctors, plumbers). In order to assess emotional attachment to language, participants were asked what language they tend to utilize to express themselves when they are feeling happy, and an additional question asked what language they tend to utilize to express themselves when they are feeling angry. Choices included English, Spanish, and No Choice (Both Equally).

Acculturation: language use. The Language Use subscale of the Acculturation Scale for Hispanics (Marin et al., 1987) used in Study 1 to confirm that respondents were monolingual was used to assess the level of bilingualism for each individual (see Appendix A).

\section{Materials}

The same materials used in Study 1 were used. Each word or term was translated into Spanish for use in the Spanish version of the word-emotion rating task.

\section{Design and Procedure}

Bilingual participants were presented with instructions in Spanish. Participants then completed a calibration task that included terms in both English and Spanish and two attentioncheck questions. Participants were then randomly assigned to complete the main task in either English or Spanish first. The order of language presentation for each of the main rating tasks was randomized per participant in order to minimize the possibility of sequence effects. Following the rating tasks, participants completed the demographics questionnaire and acculturation scale in Spanish.

\section{Results}

\section{Language Preference: Descriptive Statistics}

Data were collected from two different sources in order to classify participants' language preference for communication: The Acculturation Scale for Hispanics (Marin et al., 1987) and 
the set of three demographics questions directly asking about language choice when (a) receiving technical information, (b) expressing happiness, and (c) expressing anger. The five questions in the acculturation scale were summed (range: 5 to 25 ). The three questions that asked about language preference were also summed (range: 3 to 9). All individual items were significantly correlated at $p \leq .001$ with $r$ values ranging from .33 to .68 . The overall acculturation score and the overall language preference scores were significantly correlated, $r(124)=.66, p \leq .001$

\section{Research Questions}

Research Question 4 addresses whether emotional response ratings for English and Spanish terms correlated when rated by bilingual speakers. Of particular interest was whether any ABA terms show large differences in emotional response in English and Spanish. In order to answer this question, mean ratings and standard deviations for each term were derived for each language (Spanish and English). Means and standard deviations for pairs of terms are presented in Table D-8 (ABA terms), Table D-9 (General Psychological terms), Table D-10 (Control words), and Table D-11 (Calibrator words). The fifth column of Tables D-8 through D-11 shows the correlation between the term in English and in Spanish. Overall, it is notable that most terms rated in English and Spanish by bilingual individuals were highly correlated.

As reported in Table D-8, emotional valence ratings for 32 out of 36 of the ABA terms in English and Spanish were significantly correlated $(p<.05)$. For the General Psychology Terms, 29 out of 32 terms were highly correlated $(p<.01)$ and 3 out of 32 were significantly correlated $(p<.05)$ (see Table D-9). All 13 English and Spanish Control words were highly correlated ( $p<$ .01 ; see Table D-10). Finally, as can be seen in Table D-11, emotional valence ratings for all nine Calibrator words in English and Spanish were highly correlated $(p<.01)$. Thus, the current results suggest that ABA and General Psychological technical jargon had similar emotional 
response ratings in both English and Spanish when rated by Bilingual speakers.

To explore if there were any ABA terms that showed large differences in emotional response in English and Spanish, paired-samples $t$-tests were conducted. As can be seen in Table D- 8, there were significant differences for the following pairs of ABA terms in English and Spanish: shaping/moldeamiento; preference assessment/evaluación de preferencias; elopement/conducta de fuga; generalization/generalización; differential reinforcement/reforzamiento demorado; time-out/tiempo fuera; incompatible behavior/conducta incompatible; and deprivation/privación. Given the number of $t$-tests, however, this finding should be interpreted with caution (discussed in more detail below).

Research Question 5 addressed whether a bilingual individual's emotional response ratings made to the same terms in English and Spanish is related to their preferred language for communication (English, Spanish, or bilingual) based on their acculturation score. To address this question, I first computed a difference score between ratings for the same term in Spanish and English. Difference scores could range from -8 (English has stronger happiness rating) to +8 (Spanish has stronger happiness rating) with a 0 indicating no emotional valence rating difference between the two languages. Next, correlations between acculturation score and difference scores were computed. The seventh column in Tables D-8 through D-11 show these correlations. A positive correlation means that the more strongly Spanish a bilingual person is, the more the Spanish term was rated higher compared to its English equivalent. Similarly, the more strongly English a bilingual a person is, the more the English term was rated higher than its Spanish equivalent. In contrast, a negative correlation indicates that the more strongly Spanish dominant a bilingual person is, the more the English term was rated higher than Spanish and the more English a bilingual person is, the more the Spanish term was rated higher than English. As 
can be seen in Table D-8, there was a significant negative correlation $(p<.05)$ between the difference score for stimulus/estimulo and acculturation in the ABA word list. Similarly, Table D-10, shows that there was a significant positive correlation $(p<.05)$ between the difference score for give/regalar and acculturation score in the Control word list. Overall, however, there appears to be very little relationship between acculturation score and differences between English and Spanish ratings of emotional valence by bilingual individuals.

A similar procedure was completed to answer the question related to preferred language for expressing emotions. For Research Question 6 (angry) the correlations are shown in the eighth column of Tables D-8 through D-11, and for Research Question 7 (happy) the correlations are in the $9^{\text {th }}$ column of Tables D- 8 though D- 11 . Column 8 in Table D- 8 shows correlations of difference scores with language preference when angry. For the ABA terms, there were significant positive correlations $(p<.05)$ between language preference when upset and the difference scores for positive reinforcement/reforzamiento positivo and reinforcement schedule/programa de reforzamiento. For the General Psychological word list there were significant positive correlations $(p<.01)$ between the difference scores for praise/alabanza and behavior modification/modificación de comportamiento $(p<.05)$ and language preference when upset, but significant negative correlations between the difference scores for tantrum/berrinche and play therapy/terapia ludica and language preference when upset. Lastly, there was a significant positive correlation $(p<.05)$ between the difference score for knowledge/sabiduria and language preference when upset in the Control word list. There were no significant correlations between difference scores and language preference when angry in the Calibrator word list. 
Finally, the ninth column in Tables D-8 through D-11 shows correlations of difference scores with language preference when happy. There were no significant correlations between difference score with language preference when happy in the ABA word list. There was a significant negative correlation between the difference score for learned helplessness/indefensión aprendida $(p<.01)$ and the difference score for tantrum/berrinche $(p<.05)$ and language preference when happy in the General Psychological word list. There was a significant positive correlation $(p<.05)$ between the difference score for hug/abrazo and language preference when happy in the Calibrator word list. There were no significant correlations between difference scores and language preference when happy in the Control word list.

\section{Study 2 Discussion}

The focus of Study 2 was to investigate differences and similarities in word emotion ratings for English terms and their Spanish translations made by bilingual speakers and to explore whether language acculturation and language preference for expressing emotion is related to differences in emotion ratings for the two languages.

Emotional response ratings for English and Spanish terms were correlated when rated by bilingual speakers. The results showed that bilingual individuals tended to rate terms in both English and Spanish very similarly when rating emotional valence, and this was true for all categories of terms (i.e., Calibrators, Control, ABA terms, General Psychological terms). Furthermore, I explored whether there were specific terms where there were notable differences between bilingual participants' ratings in English and Spanish. There were significant differences for 8 of the $36 \mathrm{ABA}$ terms. This finding should be interpreted with caution due to the number of $t$-tests conducted. It is also important to note that many of the terms have an additional meaning in one or both languages. For example, the word "elopement" has an alternate meaning in the 
English vernacular related to marriage, whereas the translated ABA term in Spanish refers to "behavior of flight." However, the terms "generalization" and "generalización" are almost identical in English and Spanish. It would therefore be pure speculation as to why these were rated differently in each language by bilingual participants. Other terms, such as "tiempo-fuera" is a direct translation of the English term "time out." However, in Latinx American families, the term "tiempo-fuera" is not very commonly used with children as a consequence. Instead, children might be accustomed to hearing the word "castigo" (punishment) to communicate that they are being placed in time-out or will be grounded from reinforcing activities. Furthermore, in some cases the hybrid term "un time-out" might be used in bilingual contexts such as home or school. Although there were some notable differences, there is not an obvious single pattern to explain why these differences might exist.

I also explored whether bilingual speakers' emotional response ratings for the same terms in English and Spanish are related to their preferred language for communication. After computing correlations between acculturation scores and emotional response rating difference scores (Spanish-English rating), there were very few significant correlations (positive or negative). This pattern means that there was very little relationship between acculturation score and differences between English and Spanish ratings of emotional valence by bilingual speakers. Additionally, emotional ratings in English and Spanish for General Psychological terms were not related to language dominance in bilingual speakers.

Previous research has suggested that bilingual individuals express emotions in a different way depending on the language they are using at the time (Marian \& Kaushanskaya, 2008). In Study 2 I explored whether the emotional response ratings made by bilingual speakers to the same terms in English and Spanish were related to their preferred language for expressing 
negative (angry) and positive (happiness) emotions. There was a significant positive correlation between difference scores and language preference when angry for only two terms from the ABA word list and for four words from the general psychology list (two significant positive correlations and two significant negative correlations). There were no observed correlations between difference scores and language preference when expressing happiness in the ABA word list. Two negative correlations were found between difference scores and language preference when happy in the General Psychological word list ("learned helplessness" and "tantrum"). These results support the idea that while there were some relationships between language dominance and emotional response to specific words, those relationships were minimal. Therefore, Bilingual participants rated ABA terms and General Psychological terms as largely equivalent regardless of language dominance. The implications of these findings for clinical work with bilingual clients will be discussed in Chapter V. 


\section{CHAPTER V: CONCLUSION}

\section{General Discussion}

Applied Behavior Analysis is a well-established, effective, evidence-based approach to clinical and behavioral practice (e.g., National Autism Center, 2015). The image of applied behavior analysts among individuals outside the field, however, is not always positive. Bailey (1991) suggested that ABA has a "marketing problem" (p. 447) because its practitioners and interventions are viewed as unpleasant or undesirable. Previous research has shown that many jargon words used in the practice of ABA may elicit unpleasant emotional responses in clients or parents of child clients. Unpleasant emotional responses have the potential to interfere with communication between practitioners and clients or may result in clients seeking alternate forms of treatment.

Critchfield et al. (2017) examined emotional responses to words that can be considered jargon in science, clinical work, and behavioral assessment. These terms had established normative ratings reported by Warriner et al. (2013). As the authors predicted, the ABA terms they selected from the corpus were rated as more unpleasant than other professional terms and more unpleasant than English words generally (Critchfield et al., 2017). In order to extend this work, the current study assessed the emotional responses native English speakers and Bilingual Spanish-English speakers have to ABA and General Psychological jargon.

Through my replication and extension of previous work, I examined how the emotional response ratings of valence and arousal for ABA technical terms published previously compared to the novel ratings collected in the current study. After comparing 13 ABA terms that have 
established norms to ratings made by participants, the results showed that ratings made by participants in the current study are largely consistent with the norms in the established corpus.

I compared the ratings of $36 \mathrm{ABA}$ terms and 33 General Psychological terms with English language words in general by constructing 10 decile bins for the Warriner et al. corpus of almost 14,000 words. Many of the ABA terms in the current study appeared to be rated as more pleasant than ratings from previous word emotion rating work. However, it is important to highlight that on a nine-point rating scale, the highest rated $\mathrm{ABA}$ term (positive reinforcement) was rated at a 7.25. The remainder of the terms that were rated above the mid-point on the pleasantness dimension had a mean valence of 5.0, indicating that even though they were classified in the "high valence" category they were at the lower end of the category cutoff. Additionally, General Psychological terms were found to be experienced as unpleasant, if not more unpleasant, than ABA terms. As previously stated, about $70 \%$ of the participants in both conditions had taken one or more psychology courses. It is possible that this contrasting finding could be due to the context that was set up in the current study by asking individuals to rate 71 terms related to psychology out of 94 total words. Note also that several of the Control and Calibrator words could be considered peripherally related to psychological concepts (e.g., smile, relax, dream, knowledgeable, sex, suicide, hug, laughter). Therefore, it may have been difficult for participants to distinguish between ABA technical terms and General Psychological terms used in practice as explained by the spreading activation mechanism proposed by Anderson (1983) and described in Chapter IV.

My second study focused on bilingual (English and Spanish) speakers because past research suggests that even within the same individual, emotional responses are not necessarily equivalent for "equivalent" translated terms (e.g., Pavlenko, 2008). I asked Bilingual individuals 
to rate terms in both English and Spanish on the valence dimension ("Unhappy" to "Happy" and "Infeliz" to "Feliz"). Because of challenges faced by participants with the arousal dimension in Study 1, the ratings of "Calm" to "Excited" were not collected in Study 2.

I compared emotional ratings made in English and Spanish taking into account each rater's level of acculturation, which roughly corresponds to degree of comfort in each language. Study 2 focused on addressing differences and similarities in word emotion ratings made by bilingual speakers and to explore whether language acculturation and language preference for expressing emotion had an influence on these emotion ratings. The results of the current study show that bilingual individuals rated terms in both English and Spanish very similarly when rating the emotional valence of the words in all four categories: Calibrator words, Control words, ABA terms, and General Psychological terms. It is possible that Bilingual individuals who are heavily immersed in both the English and Spanish languages understand the meaning of the same word (e.g., "consequence" vs. "consecuencia") as having similar emotional connotations.

Study 2 also assessed whether there were specific terms where there were notable differences between bilingual participants' ratings in English and Spanish. Although there were 8 out of $36 \mathrm{ABA}$ terms with significant differences, this finding should be interpreted with caution due to the number of $t$-tests conducted. For $36 t$-tests, it was expected that a handful of terms would be significant due to chance itself (i.e., about $5 \%$ or 2 of 36). Using an adjusted alpha level to account for the multiple tests (e.g., using .05/36 $=.001$ ), only 3 of the differences would be considered statistically significant. Given the expectation of this many significant findings due to chance alone, the differences should not be over-interpreted.

Another important note, however, is the fact that many of the terms have additional meanings in one of the two languages. Individuals may have had a different emotional response 
to a specific word based on the meaning the word has in the vernacular rather than the meaning the word has within the field of ABA (e.g., discrimination). While there were some differences, there was no specific, obvious pattern for the set of words rated differently in English and Spanish, and it is difficult to explain why these particular terms were rated differently in the two languages. Overall, the conclusion from the pattern of findings is that emotional valence ratings for English ABA terms and their Spanish translations are correlated. This same conclusion can be drawn for English psychological terms and their Spanish translations.

The current study also explored whether a Bilingual individual's emotional response ratings for the same terms in English and Spanish is related to their preferred language for communication (English, Spanish, or bilingual). The results suggested that there is a small relationship between acculturation and differences between English and Spanish ratings of emotional valence by Bilingual speakers. Similarly, there were very few significant correlations when assessing whether the emotional response ratings made by Bilingual speakers to the same term in both languages were related to their preferred language for expressing negative (angry) and positive (happy) emotions. Overall, the answer to these research questions is that due to the high correlations between English and Spanish terms, there appears to be little relationship between differences in English and Spanish terms and the measures of language preference in Bilinguals. It is possible that because both English and Spanish derive from Latin, the cognates present (e.g., generalization vs. generalización) add to the lack of differences in ratings found between words. Furthermore, the Bilingual sample in this study identified as highly proficient in both languages. As such, it is possible that the connotation of words in both languages evoke similar emotional responses. 


\section{Strengths and Limitations of the Current Study}

One strength of the current study was that it examined novel emotional ratings from a novel sample of participants. Previous studies have assessed the emotional response ratings to various ABA and General Psychological terms. However, these assessments have been conducted through examinations of word emotion ratings of these words established in published norms (e.g., Warriner et al., 2013). Obtaining novel ratings from a large sample of individuals from the general population is beneficial because it allows us to draw conclusions about the emotional responses individuals have to technical jargon in the context of other jargon terms. Furthermore, the ability to obtain novel ratings of ABA and General Psychological terms allowed for the introduction of a new range of terms that were more representative of technical language by being able to obtain ratings for compound terms (e.g., "positive reinforcement", “early intensive behavioral intervention") commonly used in clinical and therapeutic settings.

Another strength of this study was in the examination of emotional responses to technical jargon by English-Spanish bilingual individuals. Critchfield and Doepke (2018) found that behavior analysis terms elicit negative emotions in five languages. However, their results were limited by the available norms in the existing language corpora, and their examination focused on monolingual speakers, rather than Bilingual speakers. Based on the effects that have been found in previous research, it was important to examine the emotional responses Bilingual individuals have to jargon in both languages, particularly with respect to the fact that the answer to this research question has potential implications for treatment delivery. Prior to the current study, it was unclear how bilingual individuals would react to technical jargon in both languages. As noted in Chapter II, Pavlenko (2008) suggested that emotional attachment to a language might be important. Therefore, being Bilingual may mean that one has a different level of 
emotional attachment to one language as opposed to the other. However, in the current study, any potential effect of language attachment was not overly evident. Although the results of the current study show that bilingual individuals have similar emotional responses to technical terms in both languages, it is important for practitioners to be aware of the results of the current study when working with individuals who identify as Bilingual. That is, there may be no specific advantage to conduct therapy sessions in one language over the others for those who are fluently bilingual. The same cautions for using technical jargon apply regardless of language.

One limitation of the current study is that words were presented to individuals one at a time without additional context. It is therefore difficult to assume that participants knew the meaning of each of the words/terms presented. The lack of context for words that have more than one meaning (e.g., "chain" or "extinction") means that alternate interpretations for those ratings are possible. Similarly, there may have been words for which some participants may have been unclear about the meaning. Although $70 \%$ of the participants had taken at least one psychology course, $30 \%$ of the participants may not have been familiar with all of the terms (e.g., "learned helplessness" or "stereotypy"). The lack of a meaning for some terms may have caused individuals to have a different emotional response than they would have if they clearly knew the meaning of each term or were able to derive meaning from context.

Another limitation of the present investigation is that I was unable to recruit a large sample of monolingual native Spanish speakers to complete the word-rating task. Previous research by Critchfield and Doepke (2018) found that native Spanish speakers rated ABA technical jargon just as unpleasant as native English speakers, although they were limited to using existing published norms as well. Given that the current study added and examined new 
compound ABA terms and General Psychological terms, it would have been beneficial to examine data from monolingual Spanish speakers as well.

A limitation related to the emotional dimensions measured was that the arousal ratings that were measured in Study 1 were not included in Study 2. Arousal ratings were an area of interest because they are related to Skinner's (1953) description of emotions as motivating operations that make some behaviors more or less reinforcing to engage in (Critchfield \& Doepke, 2018). After analyzing the data from Study 1, however, the correlations between participant ratings and established norms were non-significant or negative for the majority of participants in the arousal condition. Participants clearly found it difficult to apply the "Calm" to "Excited" anchors to the ABA and General Psychological terms while at the same time they were making ratings consistent with those of established norms for the Control and Calibrator words. It was assumed that the same difficulty would apply to the task when conducted in Spanish using the "Tranquilo/Tranquila" and "Exitado/Exitada" anchors. Therefore, I did not examine arousal ratings for bilingual participants.

Lastly, another limitation of the current study was that the measures utilized in Study 2 assessed language preference when expressing oneself, but the rating task the participants completed in the current study focused on receptive language. For instance, the Language Use subscale of the Acculturation Scale asked participant to answer questions related to language spoken at home, language spoken as a child, and language spoken with friends. Similarly, the language preference questions asked participants to answer questions related to language preference when expressing happiness and anger. It would therefore be beneficial to include measures that assess receptive language to match the rating scale used in the current study. 


\section{Directions for Future Research}

Based on the various limitations in the current study, there are many potential directions for future research on emotional responses to ABA and psychological jargon. Researchers are encouraged to find a large representative sample of native Spanish speakers. As the word rating procedure is relatively simple to use, it would be feasible to appropriately translate the task to meet the needs of the native Spanish speaking population. With the growing population of the Latinx community in the United States, it is important to ensure that we find the best language to communicate with this population in therapy settings.

Future researchers should find an alternate way to present the arousal dimension to study emotional responses to technical jargon terms. The results of the current study showed that the inconsistent arousal ratings may have been due to the confusion caused by the anchors "Calm" to "Excited." This confusion was not evident for the ratings made to calibrator and control words such as "party" or "meditation" and so there was something about asking participants to apply these terms to psychological and ABA jargon that they found difficult or unclear. Future research might assess and apply more appropriate anchor descriptors to ensure that the measurement of the "arousal" dimension. Perhaps the anchors "Not Motivating" to "Motivating" might be easier for subjects to use and apply in a rating task. In order to address how arousal and valence interact to influence an overall emotional response to words or terms, it is important to have a reliable and valid method of assessing word emotion arousal.

Another consideration for future research is developing an assessment method whereby technical terms can be studied in a more meaningful context. Although the current study may have provided context in the form of asking participants to rate a large number of terms pertaining to the field of psychology, context could be specifically provided by asking 
participants to rate terms they read about in vignettes describing intake or therapy sessions. This procedure would enable comparisons to simple-language equivalents. For instance, participants could read a vignette describing an ABA treatment to a parent using technical jargon (e.g., "reinforce") and read another vignette using simple language (e.g., "praise" or "reward"). Such comparisons could produce findings that would allow practitioners to consider alternate methods of communication about ABA concepts with individuals in clinical and applied settings.

An important consideration for the current research is the relationship between culture and language. As Jiang (2000) stated, language is an important part of culture. Jian described language as a component that defines culture but that is also influenced and shaped by it. Although the results of the current study suggest that technical language has unpleasant overtones in both English and Spanish, it would be important to delve into the differences within the Bilingual individuals' various cultures. Even though it can be difficult to define what it truly means to be Bilingual, the responses between a Bilingual individual who identifies as Latinx and a Bilingual individual who identifies as White could have a large impact in the emotional responses to specific terms based on their different cultural backgrounds. It is therefore important for future research to consider the relationship between culture and language and assess these differences when studying the emotional impact of jargon.

\section{Clinical Implications}

There has been a growing concern that the vocabulary used by practitioners in the field of ABA causes distance between the individual practitioners who deliver ABA services and the clients who are searching for behavioral services. As Critchfield et al. (2017) emphasized, the vocabulary of behavior analysis has remained consistent since it was first developed from the 1930s to the 1950s. It is important to recognize, however, that the client base in need of support 
from the field of $\mathrm{ABA}$ is continually changing and growing. A major focus of the field is the dissemination and application of theories (Baer et al., 1968), and it is the field's ethical responsibility to adhere to the commitment to the clients who need support.

Based on the results from previous research and the current study, it is important to recognize that $\mathrm{ABA}$ technical language and General Psychological technical language can elicit unpleasant emotional responses. In addition, the current study adds the finding that Bilingual Spanish and English speakers have a similar unpleasant emotional response to technical terms in both languages. It is therefore important for the field to begin seeking new terms that evoke more positive emotional responses to improve communication and rapport between clients and therapists.

The results of the current study could also be used to encourage practitioners to reflect on the impact of mental health related stigma. Although there is an understanding that mental health support can and should be positive, there may still be an unconscious stigma associated with the field in general. The finding that behavioral and psychological terms that are experienced as unpleasant may be related to the fact that individuals often avoid or delay seeking mental health support due to the stigma and/or embarrassment associated with it. For instance, Clement et al. (2015) conducted a meta-analysis that suggested that stigma has a clear effect, albeit small to moderate sized, for seeking mental health support and there is a need for new interventions that can help minimize the effect of perceived stigma. Clement et al. suggested that one method to decrease mental health stigma is through by reaching out to the community and providing psycho-education about the field of mental health and the services available to potential clients. Although this suggestion may be a great opportunity for mental health professionals to help decrease the stigma associated with mental illness and treatment, it is important to consider the 
emotional valence associated with terms related to mental health or psychological jargon before providing such psycho-education. If this factor is not considered, then providing psychoeducation with jargon may cause more damage and continue increasing the gap between therapists and individuals who are in need of mental health services.

Furthermore, with the growing Bilingual population, it is important to find the best methods to increase communication in various languages. As noted in Chapter II, the ABA community has produced glossaries of technical terms in several languages, including Spanish (https://www.bacb.com/wp-content/uploads/2017/09/ Spanish-English-ABA-Glossary.pdf). However, there has been minimal research on how individuals outside the field of ABA actually understand or experience these terms. Many of these terms have been literally translated, which means that individuals in the Latinx community may have a difficult time understanding the meaning of these translated words, even if the argument is that the words are in their native language. Additionally, many translators who are hired from various agencies may not have the background to understand and explain to a client that the word "discrimination" for example, does not have the same meaning in the field of $\mathrm{ABA}$ as it does in the vernacular. Therefore, using literal translations may cause more harm in a therapeutic relationship. A similar problem may arise when therapists who are native English speakers try to use the glossary to communicate using some Spanish for their clients. While therapists in this situation are trying to enhance communication with their clients, using literal translations may also cause significant harm and impair communication.

Overall, jargon can be an efficient and effective way to communicate within a community of professionals within the same field. However, when communicating with members outside the field, as when communicating with a client, a parent of a client, or a teacher of a client, there is a 
potential for damage to the therapeutic relationship based on the language used to communicate.

It is therefore important to continue exploring various methods to decrease the potential to transmit unintended emotional baggage and increase the accuracy and ease of communication between client and therapist. 


\section{REFERENCES}

Anderson, J.R. (1983). A spreading activation theory of memory. Journal of Verbal Learning and Verbal Behavior, 22, 1-33.

Anooshian, L. J. \& Hertel, P. T. (1994). Emotionality in free recall: A case of language specificity in bilingual memory. Cognition and Emotion, 8, 503-514.

Aragno, A. \& Schlachet, P. (1996). Accessibility of early experience through the language of origin: A theoretical integration. Psychoanalytic Psychology, 13, 1, 23-34.

Ayllon, T. \& Michael, J. (1959). The psychiatric nurse as a behavioral engineer. Journal of the Experimental Analysis of Behavior, 2, 323-334.

Baer, D. M., Wolf, M. M., \& Risley, T. R. (1968). Some still-current dimensions of applied behavior analysis. Journal of Applied Behavior Analysis, 1, 91-97.

Bailey, J. S. (1991). Marketing behavior analysis requires different talk. Journal of Applied Behavior Analysis, 24, 445-448. doi:10.1901/jaba.1991.24-445.

Becirevic, A., Critchfield, T. S., \& Reed, D. D. (2016). On the social acceptability of behavioranalytic terms: crowdsourced comparisons of lay and technical language. The Behavior Analyst. Advance on- line publication. doi:10.1007/s40614-016-0067-4.

Blumenfeild, H.K. \& Marian, V. (2007). Constraints on parallel activation in bilingual spoken language processing: Examining proficiency and lexical status using eye-tracking. Language and Cognitive Processes, 22, 633-660.

Bolling, M. (2002). Research and representation: A conundrum for behavior analysts. Behavior and Social Issues, 12, 19-28.

Bond, M. H. \& Lai, T. M. (1986). Embarrassment and code-switching into a second language. Journal of Social Psychology, 126, 179-186. 
Bradley, M. M. \& Lang, P. J. (1999). Affective norms for English words (ANEW): Stimuli, instruction manual and affective ratings (Technical Report No. C-1). Gainesville, FL: University of Florida, NIMH Center for Research in Psychophysiology.

Clement, S., Schauman, T., Graham, F., Maggioni, F., Evans-Lacko, S., Bezborodovs, N., Morgan, C., Rüsch, N., Brown, J.S.L., \& Thornicroft, G. (2015). What is the impact of mental health-related stigma on help-seeking? A systematic review of quantitative and qualitative studies. Psychological Medicine, 45, 11-27.

Critchfield, T., Becirevic, A., \& Reed, D. (2017). On the social validity of behavior-analytic communication: A call for research and description of one method. The Analysis of Verbal Behavior, 33, 1-23.

Critchfield, T. \& Doepke, K. (2018). Emotional overtones of behavior analysis terms in English and five other languages: A preliminary comparison. Behavior Analysis in Practice, 11, 97-105. DOI: 10.1007/s40617-018-0222-3.

Deitz, S. M. \& Arrington, R. L. (1983). Factors confusing language use in the analysis of behavior. Behaviorism, 11, 117-132.

Dodds, P. S., Clark, E. M., Desu, S., Frank, M. R., Reagan, A. J., Williams, J. R., ...\& Danforth, M.C. (2015) Human language reveals a universal positivity bias. Proceedings of the National Academy of Sciences, 112, 2389-2394. doi:10.1073/pnas.1411678112.

Durand, V. M. (1987). “Look homeward angel”: A call to return to our (functional) roots. Behavior Analyst, 10, 299-302.

Elliot, S.N. (1988). Acceptability of behavioral treatments: Review of variables that influence treatment selection. Professional Psychology: Research and Practice, 19, 68-80. https://doi.org/10.1037/0735-7028.19.1.68. 
Foxx, R. M. (1996). Translating the covenant: The behavior analyst as ambassador and translator. The Behavior Analyst, 19, 147-161.

Goldman, S. R. \& Bisanz, G. L. (2002). Toward a functional analysis of scientific genres: Implications for understanding and learning processes. In J. Otero, J. A. Leon, \& A. C. Graesser (Eds.), The psychology of science text comprehension (pp. 19-50). Mahwah, NJ: Erlbaum.

Ha, J.F., Anat, D.S., \& Longnecker, N. (2010). Doctor-patient communication: A review. Ochsner Journal, 10, 38-43.

Hall, G. C. N. (2001). Psychotherapy research with ethnic minorities: Empirical, ethical, and conceptual issues. Journal of Consulting and Clinical Psychology, 69, 502-510.

Hallenstein, E.B. (1978). Ethical problems of psychological jargon. Professional Psychology, 9, 111-116.

Harms, P. D. and DeSimone, J. A. (2015). Caution! Mturk workers ahead - Fines doubled. Industrial Organizational Psychology, 8, 183-190. doi: 10.1017/iop.2015.23

Harzem, P. \& Miles, T. R. (1978). Conceptual Issues in Operant Psychology. London: John Wiley and Sons.

Jacobson, J. W. \& Holburn, S. (2004). History and current status of applied behavior analysis in developmental disabilities. In J. L. Matson, R. B. Laud, \& M. L. Matson (Eds.), Behavior modification for persons with developmental disabilities: Treatments and supports (Vol. 1, pp. 1-32). Kingston: NADD Press.

Jarmolowicz, J. P., Kahng, A., Invarsson, E. T., Goysovich, R., Heggemeyer, R., \& Gregory, M. K. (2008). Effects of conversational versus technical language on treatment preference and integrity. Intellectual and Developmental Disabilities, 46, 190-199. 
Javier, R. (1995). Vicissitudes of autobiographical memories in a bilingual analysis. Psychoanalytic Psychology, 12, 3, 429-438.

Jay, T. B. \& Janschewitz, K. (2007). Filling the emotion gap in linguistic theory: Commentary on Potts' expressive dimension. Theoretical Linguistics, 33, 215-221.

Jiang, W. (2000). The relationship between language and culture. ELT Journal, 4, 328-334.

Keith, M.G., Tay. L., \& Harms, P.D. (2017). Systems perspective of amazon mechanical turk for organizational research: Review and recommendations. Frontiers in Psychology, 8, 1-19.

Klahr, D. \& Li, J. (2005). Cognitive research and elementary science instruction: From the laboratory, to the classroom, and back. Journal of Science Education and Technology, 14, 217-238. DOI: 10.1007/s10956-005-4423-5.

Lindsley, O. R. (1991). From technical jargon to plain English for application. Journal of Applied Behavior Analysis, 24, 449-458. doi:10.1901/jaba.1991.24-449.

Marian, V. \& Kaushanskaya, M. (2008). Words, feelings, and bilingualism: Cross-linguistic differences in emotionality of autobiographical memories. The Mental Lexicon, 3, 1, 7291.

Marin, G., Sabogal, E, Marin, B., Otero-Sabogal, R., \& Perez-Stable, E. (1987). Development of a short acculturation scale for Hispanics. Hispanic Journal of Behavioral Sciences, 9, 183-205.

Maurice, C. (1993). Let me hear your voice: a family's triumph over autism. New York: Random House.

Mitchell, M.M., Brown, K.M., Morris-Villagran, M., \& Villagran, P.D. (2001). The effects of anger, sadness, and happiness on persuasive message processing: A test of the negative state relief model. Communication Monographs, 68, 347-359. 
Movahedi, S. (1996). Metalinguistic analysis of therapeutic discourse: Flight into a second language when the analyst and the analysand are multilingual. Journal of the American Psychoanalytic Association, 44, 837-862.

National Autism Center. (2015). Findings and conclusions: National standards project, phase 2. Randolph, MA: Author.

Osgood, C.E., Suci, G.J., \& Tannenbaum, P. (1957). The Measurement of Meaning. University of Illinois Press.

Pavlenko, A. (2008). Emotion and emotion-laden words in the bilingual lexicon. Bilingualism: Language \& Cognition, 11, 147-164. doi:10.1017/S1366728908003283.

Pew Research Center. (2013). A majority of English-speaking Hispanics in the U.S. are bilingual (March 2013). Retrieved from http://pewresearch.org/datasets.

Reichow, B. (2012). Overview of meta-analyses on early intensive behavioral intervention for young children with autism spectrum disorders. Journal of Autism and Developmental Disorders, 42, 512-20.

Russell, J. A. \& Mehrabian, A. (1977). Evidence for a three-factor theory of emotions. Journal of Research in Personality, 11, 273-294. http://dx.doi.org/10.1016/0092-6566(77)90037-X

Skinner, B. F. (1953). Science and human behavior. New York Press.

Warriner, A. B. \& Kuperman, V. (2015). Affective biases in English are bi-dimensional. Cognition and Emotion, 29, 1147-1167. doi:10.1080/02699931.2014.968098.

Warriner, A. B., Kuperman, V., \& Brysbaert, M. (2013). Norms of valence, arousal, and dominance for 13,915 English lemmas. Behavior Research Methods, 1-17. doi:10.3758/s13428-012-0314-x

Webster's ninth collegiate dictionary. (1987). New York: Merriam-Webster. 
Witt, J. C., Moe, G., Gutkin, T. B., \& Andrews, L. (1984). The effect of saying the same thing in different ways: the problem of language and jargon in school-based consultation. Journal of School Psychology, 22, 361-367. doi:10.1016/0022-4405(84)90023-2.

Zuckerman, K.E., Mattox, K., Donelan, K., Batbayar, O., Baghaee, A.,\& Bethell, C. (2013). Pediatrician identification of Latino children at risk for autism spectrum disorder. Pediatrics, 132, 445-453. 


\section{APPENDIX A: SHORT ACCULTURATION SCALE}

\section{English Version}

1. In general, what language(s) do you read and speak?

1

2

3

4

Only Spanish Spanish better Both Equally English better

Only

than English

than Spanish

English

2. What was the language(s) you used as a child?

1

2

3

4

5

Only Spanish

Spanish better

Both Equally

English better

Only

than English

than Spanish

English

3. What language(s) do you usually speak at home?

1 2

3

4 5

Only Spanish

Spanish better

Both Equally

English better

Only

than English

than Spanish

English

4. In which language(s) do you usually think?

1

2

3

4

5

Only Spanish

Spanish better

Both Equally

English better

Only

than English

than Spanish

English

5. What language(s) do you usually speak with your friends?

1

2

Only Spanish
Spanish better
than English
3

Both Equally

English better

than Spanish
5

Only

English

\section{Spanish Version}


1. Por lo general, qué idioma(s) leé y habla usted?

1 2

Solo Español Español mejor Ambos por igual Inglés mejor que Solo Inglés que Inglés Español

2. Cual fué el idoma(s) que habló cuando era niño(a)?

1 2 Español mejor que Inglés
3

4

Ambos por igual Inglés mejor que

Español

3. Por lo general, en qué idioma(s) habla en su casa?
1
2
3
4
5

Solo Español Español mejor Ambos por igual Inglés mejor que Solo Inglés que Inglés Español

4. Por lo general, en qué idioma(s) piensa?

1

34

5

Solo Español Español mejor Ambos por igual Inglés mejor que Solo Inglés que Inglés Español

5. Por lo general en qué idioma(s) habla con sus amigos(as)?

1

2

3

4

5

Solo Español Español mejor Ambos por igual Inglés mejor que Solo Inglés que Inglés
Español 


\section{APPENDIX B: INSTRUCTIONS FOR WORD RATING TASK}

Adapted from Warriner et al. (2013)

\section{Valence Instructions}

You are invited to take part in the study that is investigating emotion, and concerns how people respond to different types of words. You will use a scale to rate how you felt while reading each word.

There will be approximately 90 words. To rate each word, you will use a scale that range from 1 (unhappy) to 9 (happy).

At one extreme of this scale, you feel completely unhappy, annoyed, unsatisfied, melancholic, despaired, or bored. You can indicate feeling completely unhappy by selecting 1.

The other end of the scale is when you feel completely happy, pleased, satisfied, contented, or hopeful. When you feel completely happy you should indicate this by choosing rating 9 .

The numbers also allow you to describe intermediate feelings by selecting other values (e.g., 2, 3,4 or $6,7,8$ ). If you feel completely neutral (neither happy nor unhappy), then select the middle of the scale (rating 5).

Please work at a rapid pace and don't spend too much time thinking about each word. Rather, make your ratings based on your first and immediate reaction as you read each word.

\section{Arousal Instructions}

You are invited to take part in the study that is investigating emotion, and concerns how people respond to different types of words. You will use a scale to rate how you felt while reading each 
word.

There will be approximately 90 words. To rate each word, you will use a scale that range from 1 (calm) to 9 (excited).

At one extreme of this scale, you feel completely relaxed, calm, sluggish, dull, sleepy, or unaroused. When you feel completely calm you should indicate this by choosing rating 1 .

The other end of the scale is when you are stimulated, excited, frenzied, jittery, wide-awake, or aroused. You can indicate feeling completely aroused by selecting 9.

The numbers also allow you to describe intermediate feelings of calmness/arousal by selecting other values (e.g., 2, 3, 4 or 6, 7, 8). If you feel completely neutral (neither excited nor calm), then select the middle of the scale (rating 5).

Please work at a rapid pace and don't spend too much time thinking about each word. Rather, make your ratings based on your first and immediate reaction as you read each word. 


\section{APPENDIX C: DEMOGRAPHICS}

\section{Demographic Information (English Version)}

Age:

Gender Identity (circle): Male Female

Other (e.g. transgender, gender queer), please specify:

\section{Marital Status: Single} Married Widowed

Racial/Ethnic Identity:

White/Caucasian

Black/African American

Hispanic/Latino

Asian/Pacific Islander

Native American

Multi-Racial/Multi-Ethnic

Other (Please Specify):

Country of Origin:

Country of Residence:

Years of Education:

$$
\begin{array}{ll}
1 \text { = some high school } & 5 \text { = Bachelor's degree } \\
2 \text { = high school } & 6 \text { = some postgraduate study } \\
3 \text { = some college } & 7 \text { = Master's degree } \\
4=\text { Associate's degree } & 8=\text { Doctorate or professional degree }
\end{array}
$$

List the number of psychology courses taken at the college level? 
What is your father's highest level of education?

What is your mother's highest level of education?

$$
\begin{array}{ll}
1=\text { some high school } & 5=\text { Bachelor's degree } \\
2=\text { high school } & 6=\text { some postgraduate study } \\
3=\text { some college } & 7=\text { Master's degree } \\
4=\text { Associate's degree } & 8=\text { Doctorate or professional degree }
\end{array}
$$

In what social class would you place your family as you were growing up?

$$
\begin{array}{ll}
1 \text { = lower class } & 4=\text { middle class } \\
2 \text { = working class } & 5=\text { upper middle class } \\
3 \text { = lower middle class } & 6=\text { upper class } \\
7 & =\text { Prefer not to answer }
\end{array}
$$

Do you have any children?

Yes

No

Do you and/or anyone in your direct family have any other serious physical, intellectual, or developmental disabilities or mental illnesses?

Yes

No 
Have you and/or anyone in your direct family received behavioral services in the past?

Yes

No

Are you and/or anyone in your direct family currently receiving behavioral services? Yes No

\section{Additional Questions for Study 2 Participants}

In which language are you more comfortable receiving new information?

For example, when you receive specialized or technical information from various kinds of experts in health fields (such as doctors, dentists, therapists, counselors, etc.) and other specializations (e.g., accountant, lawyer, car mechanic, plumber, electrician, etc.), would you rather have discussions in English, Spanish, or both/either?

English Spanish No Choice (both equally)

In times when you are very angry, what language do you tend to utilize?

English Spanish No Choice (both equally)

In times when you are very happy, what language do you tend to utilize?

English Spanish No Choice (both equally) 


\section{APPENDIX D: TABLES}

Table D-1

Percentile Bins and Valence Rating Cut-offs for the Warriner et al. Corpus and the Distribution of ABA and General Psychological Terms from the Current Study

\begin{tabular}{|c|c|c|c|}
\hline Percentile Bin & Valence rating range & ABA Terms (36) & $\begin{array}{l}\text { General Psychological } \\
\text { Terms (33) }\end{array}$ \\
\hline $0-10^{\text {th }}$ & $0-3.20$ & 5 & 13 \\
\hline $11-20^{\text {th }}$ & $3.21-3.94$ & 4 & 1 \\
\hline $21-30^{\text {th }}$ & $3.95-4.50$ & 4 & 1 \\
\hline $31-40^{\text {th }}$ & $4.51-4.89$ & 7 & 1 \\
\hline $41-50^{\text {th }}$ & $4.90-5.20$ & 3 & 3 \\
\hline $51-60^{\text {th }}$ & $5.21-5.47$ & 4 & 3 \\
\hline $61-70^{\text {th }}$ & $5.48-5.76$ & 4 & 3 \\
\hline $71-80^{\text {th }}$ & $5.77-6.14$ & 4 & 2 \\
\hline $81-90^{\text {th }}$ & $6.15-6.50$ & 0 & 1 \\
\hline $91-100^{\text {th }}$ & $6.51-9$ & 1 & 5 \\
\hline
\end{tabular}


Table D-2

Descriptive Statistics for ABA Terms in Study 1

\begin{tabular}{|c|c|c|c|c|c|c|}
\hline ABA Term & $M$ & $S D$ & $n$ & $\begin{array}{l}\text { Percentile } \\
\text { Bin }\end{array}$ & Category & Warriner Norms \\
\hline \multicolumn{7}{|l|}{ Positive Reinforcement } \\
\hline Valence & 7.25 & 1.30 & 112 & $91-99^{\text {th }}$ & Rousingly Pleasant & $\mathrm{N} / \mathrm{A}$ \\
\hline Arousal & 5.16 & 2.36 & 76 & & & $\mathrm{~N} / \mathrm{A}$ \\
\hline \multicolumn{7}{|l|}{ Satiation } \\
\hline Valence & 5.91 & 1.72 & 112 & $71-80^{\text {th }}$ & Blandly Pleasant & $\mathrm{N} / \mathrm{A}$ \\
\hline Arousal & 3.97 & 1.93 & 76 & & & $\mathrm{~N} / \mathrm{A}$ \\
\hline \multicolumn{7}{|l|}{ Stimulus } \\
\hline Valence & 5.82 & 1.43 & 112 & $71-80^{\text {th }}$ & Rousingly Pleasant $(\mathcal{})$ & $5.63(2.01)$ \\
\hline Arousal & 7.01 & 1.82 & 76 & & & $4.7(2.69)$ \\
\hline \multicolumn{7}{|l|}{ Elopement } \\
\hline Valence & 5.79 & 1.32 & 112 & $71-80^{\text {th }}$ & Rousingly Pleasant & $\mathrm{N} / \mathrm{A}$ \\
\hline Arousal & 5.91 & 1.50 & 76 & & & $\mathrm{~N} / \mathrm{A}$ \\
\hline \multicolumn{7}{|l|}{ Function } \\
\hline Valence & 5.77 & 1.32 & 112 & $71-80^{\text {th }}$ & Blandly Pleasant $(\mathcal{V})$ & $5.55(0.76)$ \\
\hline Arousal & 4.24 & 1.38 & 76 & & & $4.1(1.7)$ \\
\hline \multicolumn{7}{|l|}{ Motivating Operation } \\
\hline Valence & 5.59 & 1.53 & 112 & $61-70^{\text {th }}$ & Rousingly Pleasant & $\mathrm{N} / \mathrm{A}$ \\
\hline Arousal & 5.29 & 1.68 & 76 & & & $\mathrm{~N} / \mathrm{A}$ \\
\hline
\end{tabular}




\begin{tabular}{|c|c|c|c|c|c|c|}
\hline ABA Term & $M$ & $S D$ & $n$ & $\begin{array}{l}\text { Percentile } \\
\text { Bin }\end{array}$ & Category & Warriner Norms \\
\hline \multicolumn{7}{|l|}{ Incompatible Behavior } \\
\hline Valence & 5.58 & 1.61 & 112 & $61-70^{\text {th }}$ & Rousingly Pleasant & $\mathrm{N} / \mathrm{A}$ \\
\hline Arousal & 2.80 & 1.37 & 76 & & & N/A \\
\hline \multicolumn{7}{|l|}{ Response } \\
\hline Valence & 5.57 & 1.52 & 112 & $61-70^{\text {th }}$ & Blandly Pleasant $(\boldsymbol{V})$ & $5.95(1.5)$ \\
\hline Arousal & 4.57 & 1.72 & 76 & & & $3.56(2.2)$ \\
\hline \multicolumn{7}{|l|}{ Reinforce } \\
\hline Valence & 5.53 & 1.32 & 112 & 61-70th & Rousingly Pleasant $(x)$ & 5.53 (1.5) Blandly pleasant \\
\hline Arousal & 5.21 & 1.51 & 76 & & & $3.96(2.33)$ \\
\hline \multicolumn{7}{|l|}{ Escape } \\
\hline Valence & 5.42 & 2.13 & 112 & $51-60^{\text {th }}$ & Rousingly Pleasant $(\boldsymbol{V})$ & $5.50(1.76)$ \\
\hline Arousal & 6.63 & 1.92 & 76 & & & $4.55(2.58)$ \\
\hline \multicolumn{7}{|l|}{ Establishing Operation } \\
\hline Valence & 5.35 & 1.21 & 112 & $51-60^{\text {th }}$ & Blandly Unpleasant & N/A \\
\hline Arousal & 4.66 & 1.50 & 76 & & & N/A \\
\hline \multicolumn{7}{|l|}{ Shaping } \\
\hline Valence & 5.29 & 1.26 & 112 & $51-60^{\text {th }}$ & Blandly Pleasant & N/A \\
\hline Arousal & 4.34 & 1.50 & 76 & & & N/A \\
\hline \multicolumn{7}{|l|}{ Behavior } \\
\hline Valence & 5.26 & 1.15 & 112 & $51-60^{\text {th }}$ & Blandly Pleasant $(\mathcal{V})$ & $5.28(1.71)$ \\
\hline Arousal & 4.82 & 1.14 & 76 & & & $4.27(2.16)$ \\
\hline
\end{tabular}




\begin{tabular}{|c|c|c|c|c|c|c|}
\hline ABA Term & $M$ & $S D$ & $n$ & $\begin{array}{l}\text { Percentile } \\
\text { Bin }\end{array}$ & Category & Warriner Norms \\
\hline \multicolumn{7}{|l|}{ Preference Assessment } \\
\hline Valence & 5.07 & 1.55 & 112 & $41-50^{\text {th }}$ & Blandly Pleasant & $\mathrm{N} / \mathrm{A}$ \\
\hline Arousal & 4.46 & 1.26 & 76 & & & N/A \\
\hline \multicolumn{7}{|l|}{ Contingency } \\
\hline Valence & 4.91 & 1.15 & 112 & 41-50th & Blandly Unpleasant ( $(\mathcal{)}$ & $4.67(1.68)$ \\
\hline Arousal & 4.46 & 1.54 & 76 & & & $3.22(2.39)$ \\
\hline \multicolumn{7}{|l|}{ Operational Definition } \\
\hline Valence & 4.89 & 1.11 & 112 & $31-40$ th & Blandly Unpleasant & $\mathrm{N} / \mathrm{A}$ \\
\hline Arousal & 4.22 & 1.55 & 76 & & & N/A \\
\hline \multicolumn{7}{|l|}{ Token Economy } \\
\hline Valence & 4.85 & 1.34 & 112 & $31-40$ th & Blandly Unpleasant & N/A \\
\hline Arousal & 4.39 & 1.53 & 76 & & & N/A \\
\hline \multicolumn{7}{|l|}{ Brief FA } \\
\hline Valence & 4.81 & 1.35 & 112 & $31-40^{\text {th }}$ & Blandly Unpleasant & $\mathrm{N} / \mathrm{A}$ \\
\hline Arousal & 4.25 & 1.42 & 76 & & & N/A \\
\hline \multicolumn{7}{|l|}{ Antecedent } \\
\hline Valence & 4.79 & 1.04 & 112 & $31-40^{\text {th }}$ & Blandly Unpleasant & N/A \\
\hline Arousal & 4.36 & 1.55 & 76 & & & N/A \\
\hline \multicolumn{7}{|l|}{ Target Behavior } \\
\hline Valence & 4.72 & 1.33 & 112 & $31-40^{\text {th }}$ & Blandly Unpleasant & N/A \\
\hline Arousal & 4.95 & 1.63 & 76 & & & N/A \\
\hline
\end{tabular}




\begin{tabular}{|c|c|c|c|c|c|c|}
\hline ABA Term & $M$ & $S D$ & $n$ & $\begin{array}{l}\text { Percentile } \\
\text { Bin }\end{array}$ & Category & Warriner Norms \\
\hline \multicolumn{7}{|l|}{ Task Analysis } \\
\hline Valence & 4.64 & 1.32 & 112 & $31-40^{\text {th }}$ & Blandly Unpleasant & $\mathrm{N} / \mathrm{A}$ \\
\hline Arousal & 4.32 & 1.57 & 76 & & & N/A \\
\hline \multicolumn{7}{|l|}{ Generalization } \\
\hline Valence & 4.51 & 1.32 & 112 & $31-40^{\text {th }}$ & Blandly Unpleasant & $\mathrm{N} / \mathrm{A}$ \\
\hline Arousal & 4.42 & 1.50 & 76 & & & N/A \\
\hline \multicolumn{7}{|l|}{ Differential } \\
\hline Reinforcement & 4.48 & 1.39 & 112 & $21-30^{\text {th }}$ & Blandly Unpleasant & $\mathrm{N} / \mathrm{A}$ \\
\hline Valence & 4.86 & 1.57 & 76 & & & N/A \\
\hline \multicolumn{7}{|l|}{ Arousal } \\
\hline \multicolumn{7}{|c|}{ Reinforcement Schedule } \\
\hline Valence & 4.46 & 1.35 & 112 & $21-30^{\text {th }}$ & Blandly Unpleasant & $\mathrm{N} / \mathrm{A}$ \\
\hline Arousal & 4.83 & 1.47 & 76 & & & N/A \\
\hline \multicolumn{7}{|l|}{ Chain } \\
\hline Valence & 4.37 & 4.70 & 112 & $21-30^{\text {th }}$ & Rousingly Unpleasant & 4.79 (1.55) Blandly \\
\hline Arousal & 1.46 & 1.55 & 76 & & $(x)$ & $\begin{array}{l}\text { Pleasant } \\
4.05(2.33)\end{array}$ \\
\hline \multicolumn{7}{|c|}{ Early Intensive BI } \\
\hline Valence & 4.19 & 1.71 & 112 & $21-30^{\text {th }}$ & Rousingly Unpleasant & $\mathrm{N} / \mathrm{A}$ \\
\hline Arousal & 5.61 & 1.80 & 76 & & & N/A \\
\hline
\end{tabular}




\begin{tabular}{|c|c|c|c|c|c|c|}
\hline ABA Term & $M$ & $S D$ & $n$ & $\begin{array}{l}\text { Percentile } \\
\text { Bin }\end{array}$ & Category & Warriner Norms \\
\hline \multicolumn{7}{|l|}{ Delayed Reinforcement } \\
\hline Valence & 3.88 & 1.43 & 112 & $11-20^{\text {th }}$ & Rousingly Unpleasant & $\mathrm{N} / \mathrm{A}$ \\
\hline Arousal & 4.61 & 1.37 & 76 & & & N/A \\
\hline \multicolumn{7}{|l|}{ Consequence } \\
\hline Valence & 3.49 & 1.64 & 112 & $11-20^{\text {th }}$ & Rousingly Unpleasant & 3.86 (1.55) Blandly \\
\hline Arousal & 5.88 & 1.53 & 76 & & $(x)$ & $\begin{array}{l}\text { Unpleasant } \\
4.31(2.09)\end{array}$ \\
\hline \multicolumn{7}{|l|}{ Time-out } \\
\hline Valence & 3.43 & 1.63 & 112 & $11-20^{\text {th }}$ & Blandly Unpleasant & $\mathrm{N} / \mathrm{A}$ \\
\hline Arousal & 4.21 & 1.82 & 76 & & & N/A \\
\hline \multicolumn{7}{|l|}{ Stereotypy } \\
\hline Valence & 3.28 & 1.54 & 112 & $11-20^{\text {th }}$ & Rousingly Unpleasant & $\mathrm{N} / \mathrm{A}$ \\
\hline Arousal & 5.13 & 1.56 & 76 & & & N/A \\
\hline \multicolumn{7}{|l|}{ Negative Reinforcement } \\
\hline Valence & 2.28 & 1.40 & 112 & $0-10^{\text {th }}$ & Rousingly Unpleasant & $\mathrm{N} / \mathrm{A}$ \\
\hline Arousal & 6.11 & 1.67 & 76 & & & N/A \\
\hline \multicolumn{7}{|l|}{ Extinction } \\
\hline Valence & 2.01 & 1.43 & 112 & $0-10^{\text {th }}$ & Rousingly Unpleasant & $3.1(2.34)$ \\
\hline Arousal & 6.41 & 3.31 & 76 & & $(\boldsymbol{V})$ & $5.0(2.43)$ \\
\hline
\end{tabular}




\begin{tabular}{|c|c|c|c|c|c|c|}
\hline ABA Term & $M$ & $S D$ & $n$ & $\begin{array}{l}\text { Percentile } \\
\text { Bin }\end{array}$ & Category & Warriner Norms \\
\hline \multicolumn{7}{|l|}{ Deprivation } \\
\hline Valence & 2.00 & 1.16 & 112 & $0-10^{\text {th }}$ & Rousingly Unpleasant & $2.58(1.50)$ \\
\hline Arousal & 5.83 & 1.84 & 76 & & $(\boldsymbol{V})$ & $4.57(1.91)$ \\
\hline \multicolumn{7}{|l|}{ Punishment } \\
\hline Valence & 1.82 & 1.16 & 112 & $0-10^{\text {th }}$ & Rousingly Unpleasant & $2.76(1.74)$ \\
\hline Arousal & 7.13 & 1.22 & 76 & & $(\boldsymbol{V})$ & $5.07(2.51)$ \\
\hline \multicolumn{7}{|c|}{ Discrimination } \\
\hline Valence & 1.76 & 1.13 & 112 & $0-10^{\text {th }}$ & Rousingly Unpleasant & $2.45(1.43)$ \\
\hline Arousal & 6.74 & 1.54 & 76 & & $(\boldsymbol{V})$ & $5.62(2.55)$ \\
\hline
\end{tabular}

Note. Items in bold are the terms that have existing Warriner et al. (2013) norms. A $\boldsymbol{V}$ indicates that the term falls in the same category as Warriner et al. An $\boldsymbol{X}$ indicates that the term falls into a different category than Warriner et al. Percentile bins were derived from the Warriner et al. corpus of almost 14,000 words. See text for further explication. 
Table D-3

Descriptive Statistics for the General Psychological Terms in Study 1

\begin{tabular}{|c|c|c|c|c|c|c|}
\hline General Psychological Term & $M$ & $S D$ & $n$ & Percentile Bin & Category & Warriner Norms \\
\hline $\begin{array}{l}\text { Reward } \\
\text { Valence } \\
\text { Arousal }\end{array}$ & $\begin{array}{l}8.04 \\
6.67\end{array}$ & $\begin{array}{l}1.09 \\
1.94\end{array}$ & $\begin{array}{l}112 \\
76\end{array}$ & $91-100^{\text {th }}$ & $\begin{array}{l}\text { Rousingly Pleasant } \\
(\mathcal{V})\end{array}$ & $\begin{array}{l}7.47(1.35) \\
5.58(2.74)\end{array}$ \\
\hline $\begin{array}{l}\text { Praise } \\
\text { Valence } \\
\text { Arousal }\end{array}$ & $\begin{array}{l}7.80 \\
5.80\end{array}$ & $\begin{array}{l}1.26 \\
2.19\end{array}$ & $\begin{array}{l}112 \\
76\end{array}$ & $91-100^{\text {th }}$ & $\begin{array}{l}\text { Rousingly Pleasant } \\
(\mathcal{V})\end{array}$ & $\begin{array}{l}7.65(1.31) \\
5.45(2.04)\end{array}$ \\
\hline $\begin{array}{l}\text { Motivation } \\
\text { Valence } \\
\text { Arousal }\end{array}$ & $\begin{array}{l}7.21 \\
6.45\end{array}$ & $\begin{array}{l}1.40 \\
1.81\end{array}$ & $\begin{array}{l}112 \\
76\end{array}$ & $91-100^{\text {th }}$ & $\begin{array}{l}\text { Rousingly Pleasant } \\
(\mathcal{})\end{array}$ & $\begin{array}{l}6.24(2.05) \\
4.73(2.6)\end{array}$ \\
\hline $\begin{array}{c}\text { Incentive } \\
\text { Valence } \\
\text { Arousal }\end{array}$ & $\begin{array}{l}6.99 \\
6.14\end{array}$ & $\begin{array}{l}1.33 \\
1.72\end{array}$ & $\begin{array}{l}112 \\
76\end{array}$ & $91-100^{\text {th }}$ & $\begin{array}{l}\text { Rousingly Pleasant } \\
(\mathcal{V})\end{array}$ & $\begin{array}{l}7.05(1.47) \\
4.61(2.71)\end{array}$ \\
\hline $\begin{array}{l}\text { Empathy } \\
\text { Valence } \\
\text { Arousal }\end{array}$ & $\begin{array}{l}6.72 \\
2.68\end{array}$ & $\begin{array}{l}1.87 \\
1.84\end{array}$ & $\begin{array}{l}112 \\
76\end{array}$ & $91-100^{\text {th }}$ & $\begin{array}{l}\text { Blandly Pleasant } \\
(\mathcal{L})\end{array}$ & $\begin{array}{l}7.29(1.94) \\
3.62(2.06)\end{array}$ \\
\hline $\begin{array}{l}\text { Plan } \\
\text { Valence } \\
\text { Arousal }\end{array}$ & $\begin{array}{l}6.18 \\
3.74\end{array}$ & $\begin{array}{l}1.21 \\
1.76\end{array}$ & $\begin{array}{l}112 \\
76\end{array}$ & $81-90^{\text {th }}$ & $\begin{array}{l}\text { Blandly Pleasant } \\
(\mathcal{L})\end{array}$ & $\begin{array}{l}6.14(1.46) \\
3.86(2.26)\end{array}$ \\
\hline
\end{tabular}




\begin{tabular}{|c|c|c|c|c|c|c|}
\hline $\begin{array}{l}\text { General Psychological } \\
\text { Term }\end{array}$ & $M$ & $S D$ & $n$ & Percentile Bin & Category & Warriner Norms \\
\hline \multicolumn{7}{|l|}{ Feeling } \\
\hline Valence & 6.09 & 1.44 & 112 & $71-80^{\text {th }}$ & Blandly Pleasant $(\boldsymbol{V})$ & $6.50(1.95)$ \\
\hline Arousal & 4.38 & 1.93 & 76 & & & $3.86(2.57)$ \\
\hline \multicolumn{7}{|l|}{ Emotion } \\
\hline Valence & 5.89 & 1.55 & 112 & $71-80^{\text {th }}$ & Rousingly Pleasant $(\boldsymbol{V})$ & $6.62(1.88)$ \\
\hline Arousal & 5.18 & 1.87 & 76 & & & $4.75(2.79)$ \\
\hline \multicolumn{7}{|l|}{ Play Therapy } \\
\hline Valence & 5.71 & 1.71 & 112 & $61-70^{\text {th }}$ & Blandly Pleasant & $\mathrm{N} / \mathrm{A}$ \\
\hline Arousal & 4.75 & 2.19 & 76 & & & N/A \\
\hline \multicolumn{7}{|l|}{ Confidentiality } \\
\hline Valence & 5.66 & 1.52 & 112 & $61-70^{\text {th }}$ & Blandly Pleasant $(X)$ & 5.82 (1.94) Rousingly \\
\hline Arousal & 3.92 & 1.63 & 76 & & & $\begin{array}{l}\text { Pleasant } \\
4.64(2.38)\end{array}$ \\
\hline \multicolumn{7}{|l|}{ Treatment } \\
\hline Valence & 5.58 & 1.64 & 112 & $61-70^{\text {th }}$ & Blandly Pleasant $(\boldsymbol{V})$ & $5.00(1.80)$ \\
\hline Arousal & 4.09 & 1.74 & 76 & & & $4.47(2.01)$ \\
\hline \multicolumn{7}{|l|}{ Referral } \\
\hline Valence & 5.44 & 1.23 & 112 & $51-60^{\text {th }}$ & Blandly Pleasant $(X)$ & 5.52 (1.40) Rousingly \\
\hline Arousal & 4.13 & 1.46 & 76 & & & $\begin{array}{l}\text { Pleasant } \\
4.52(1.94)\end{array}$ \\
\hline \multicolumn{7}{|l|}{ Adjustment } \\
\hline Arousal & 4.36 & 1.61 & 76 & & 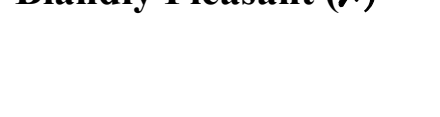 & $\begin{array}{l}\text { Pleasant } \\
4.59(2.36)\end{array}$ \\
\hline
\end{tabular}




\begin{tabular}{|c|c|c|c|c|c|c|}
\hline $\begin{array}{l}\text { General Psychological } \\
\text { Term }\end{array}$ & $M$ & $S D$ & $n$ & Percentile Bin & Category & Warriner Norms \\
\hline \multicolumn{7}{|l|}{ Client } \\
\hline Valence & 5.32 & .98 & 112 & $51-60^{\text {th }}$ & Blandly Pleasant $(\mathcal{V})$ & $5.22(1.59)$ \\
\hline Arousal & 4.05 & 1.51 & 76 & & & $2.95(1.99)$ \\
\hline \multicolumn{7}{|l|}{ Therapy } \\
\hline Valence & 5.10 & 1.79 & 112 & $41-50^{\text {th }}$ & Blandly Pleasant $(\mathcal{V})$ & $5.10(2.10)$ \\
\hline Arousal & 1.82 & 1.82 & 76 & & & 3.74 (1.89) \\
\hline \multicolumn{7}{|l|}{ Mood } \\
\hline Valence & 4.97 & 1.27 & 112 & $41-50^{\text {th }}$ & Blandly Pleasant $(X)$ & 5.29 (1.74) Rousingly \\
\hline Arousal & 3.86 & 1.72 & 76 & & & $\begin{array}{l}\text { Pleasant } \\
4.50(2.63)\end{array}$ \\
\hline \multicolumn{7}{|l|}{ Counseling } \\
\hline Valence & 4.96 & 1.77 & 112 & $41-50^{\text {th }}$ & Blandly Unpleasant & $5.90(2.13)$ \\
\hline Arousal & 3.42 & 1.58 & 76 & & $(\boldsymbol{V})$ & $3.40(2.28)$ \\
\hline \multicolumn{7}{|l|}{ Obedience } \\
\hline Valence & 4.86 & 1.92 & 112 & $31-40^{\text {th }}$ & Blandly Unpleasant & $4.63(2.09)$ \\
\hline Arousal & 3.86 & 1.67 & 76 & & $(\boldsymbol{V})$ & $3.29(2.12)$ \\
\hline \multicolumn{7}{|l|}{ Behavior Modification } \\
\hline Valence & 4.13 & 1.71 & 112 & $21-30^{\text {th }}$ & Rousingly Unpleasant & $\mathrm{N} / \mathrm{A}$ \\
\hline Arousal & 5.22 & 1.53 & 76 & & & $\mathrm{~N} / \mathrm{A}$ \\
\hline \multicolumn{7}{|l|}{ Risk Factors } \\
\hline Valence & 3.65 & 1.55 & 112 & $11-20^{\text {th }}$ & Rousingly Unpleasant & $\mathrm{N} / \mathrm{A}$ \\
\hline Arousal & 6.58 & 1.30 & 76 & & & $\mathrm{~N} / \mathrm{A}$ \\
\hline
\end{tabular}




\begin{tabular}{|c|c|c|c|c|c|c|}
\hline $\begin{array}{l}\text { General Psychological } \\
\text { Term }\end{array}$ & $M$ & $S D$ & $n$ & Percentile Bin & Category & Warriner Norms \\
\hline \multicolumn{7}{|l|}{ Learned Helplessness } \\
\hline Valence & 2.89 & 1.93 & 112 & $0-10^{\text {th }}$ & Rousingly Unpleasant & $\mathrm{N} / \mathrm{A}$ \\
\hline Arousal & 4.64 & 1.76 & 76 & & & N/A \\
\hline \multicolumn{7}{|l|}{ Delusion } \\
\hline Valence & 2.49 & 1.33 & 112 & $0-10^{\text {th }}$ & Rousingly Unpleasant & $3.30(1.84)$ \\
\hline Arousal & 5.54 & 1.65 & 76 & & $(\boldsymbol{V})$ & $4.60(2.19)$ \\
\hline \multicolumn{7}{|l|}{ Denial } \\
\hline Valence & 2.41 & 1.28 & 112 & $0-10^{\text {th }}$ & Rousingly Unpleasant & $3.57(1.78)$ \\
\hline Arousal & 5.30 & 1.67 & 76 & & $(\checkmark)$ & $4.85(2.46)$ \\
\hline \multicolumn{7}{|l|}{ Disorder } \\
\hline Valence & 2.36 & 1.34 & 112 & $0-10^{\text {th }}$ & Rousingly Unpleasant & $3.76(1.84)$ \\
\hline Arousal & 6.51 & 1.61 & 76 & & $(\boldsymbol{})$ & $4.90(2.38)$ \\
\hline \multicolumn{7}{|l|}{ Penalty } \\
\hline Valence & 2.29 & 1.29 & 112 & $0-10^{\text {th }}$ & Rousingly Unpleasant & 2.80 (1.60) Blandly \\
\hline Arousal & 6.47 & 1.60 & 76 & & $(x)$ & $\begin{array}{l}\text { Unpleasant } \\
3.89(2.45)\end{array}$ \\
\hline \multicolumn{7}{|l|}{ Tantrum } \\
\hline Valence & 2.07 & 1.33 & 112 & $0-10^{\text {th }}$ & Rousingly Unpleasant & $3.15(1.87)$ \\
\hline Arousal & 7.64 & 1.32 & 76 & & $(\mathcal{})$ & $5.05(2.36)$ \\
\hline \multicolumn{7}{|l|}{ Prejudice } \\
\hline Valence & 2.04 & 1.30 & 112 & $0-10^{\text {th }}$ & Rousingly Unpleasant & $2.71(1.95)$ \\
\hline Arousal & 6.41 & 1.45 & 76 & & $(\boldsymbol{V})$ & $5.35(2.08)$ \\
\hline
\end{tabular}

table continues 


\begin{tabular}{|c|c|c|c|c|c|c|}
\hline $\begin{array}{l}\text { General Psychological } \\
\text { Term }\end{array}$ & $M$ & $S D$ & $n$ & Percentile Bin & Category & Warriner Norms \\
\hline \multicolumn{7}{|l|}{ Chronic Stress } \\
\hline Valence & 1.98 & 1.27 & 112 & $0-10^{\text {th }}$ & Rousingly Unpleasant & $\mathrm{N} / \mathrm{A}$ \\
\hline Arousal & 6.91 & 1.30 & 76 & & & $\mathrm{~N} / \mathrm{A}$ \\
\hline \multicolumn{7}{|l|}{ Substance Abuse } \\
\hline Valence & 1.91 & 1.50 & 112 & $0-10^{\text {th }}$ & Rousingly Unpleasant & $\mathrm{N} / \mathrm{A}$ \\
\hline Arousal & 6.64 & 1.42 & 76 & & & $\mathrm{~N} / \mathrm{A}$ \\
\hline \multicolumn{7}{|l|}{ Addiction } \\
\hline Valence & 1.90 & 1.47 & 112 & $0-10^{\text {th }}$ & Rousingly Unpleasant & 3.52 (1.81) Blandly \\
\hline Arousal & 6.54 & 1.44 & 76 & & $(x)$ & $\begin{array}{l}\text { Unpleasant } \\
4.48(2.87)\end{array}$ \\
\hline \multicolumn{7}{|l|}{ Stress } \\
\hline Valence & 1.84 & 1.15 & 112 & $0-10^{\text {th }}$ & Rousingly Unpleasant & $1.79(0.92)$ \\
\hline Arousal & 7.68 & 1.31 & 76 & & $(\boldsymbol{V})$ & $4.72(2.95)$ \\
\hline \multicolumn{7}{|l|}{ Anxiety } \\
\hline Valence & 1.78 & 1.11 & 112 & $0-10^{\text {th }}$ & Rousingly Unpleasant & $\mathrm{N} / \mathrm{A}$ \\
\hline Arousal & 7.95 & 1.67 & 76 & & & $\mathrm{~N} / \mathrm{A}$ \\
\hline \multicolumn{7}{|l|}{ Depression } \\
\hline Valence & 1.33 & .73 & 112 & $0-10^{\text {th }}$ & Blandly Unpleasant & 2.44 (1.87) Rousingly \\
\hline Arousal & 4.04 & 2.02 & 76 & & $(x)$ & $\begin{array}{l}\text { Unpleasant } \\
5.2(2.09)\end{array}$ \\
\hline
\end{tabular}

Note. Items in bold are the terms that have existing Warriner et al. (2013) norms. A $\boldsymbol{V}$ indicates that the term falls in the same category as Warriner et al. An $\boldsymbol{X}$ indicates that the term falls into a different category than Warriner et al. Percentile bins were derived from the Warriner et al. corpus of almost 14,000 words. See text for further explication. 
Table D-4

Descriptive Statistics for Valence Control Words in Study 1

\begin{tabular}{lllll}
\hline Valence Control Words & $M$ & $S D$ & $n$ & Warriner Norms \\
\hline Healthy & 8.42 & .90 & 112 & $7.76(1.58)$ \\
Peace & 8.41 & .99 & 112 & $7.75(1.5)$ \\
Freedom & 8.35 & .94 & 112 & $7.72(2.12)$ \\
Smile & 8.27 & 1.11 & 112 & $7.89(2.19)$ \\
Vacation & 8.25 & 1.10 & 112 & $8.53(0.77)$ \\
Succeed & 8.19 & 1.02 & 112 & $7.05(1.68)$ \\
Relax & 8.14 & 1.06 & 112 & $7.82(2.04)$ \\
Sunshine & 8.09 & 1.21 & 112 & $8.14(1.13)$ \\
Knowledgeable & 7.69 & 1.24 & 112 & $7.95(1.12)$ \\
Summer & 7.59 & 1.65 & 112 & $7.50(1.89)$ \\
Joke & 7.43 & 1.53 & 112 & $7.88(1.44)$
\end{tabular}




\begin{tabular}{lllll}
\hline Valence Control Words & $M$ & $S D$ & $n$ & Warriner Norms \\
\hline Dream & 7.23 & 1.49 & 112 & $7.43(1.8)$ \\
Give & 7.12 & 1.49 & 112 & $7.73(1.08)$ \\
Jail & 1.54 & .94 & 112 & $1.91(1.44)$ \\
\hline
\end{tabular}


Table D-5

Descriptive Statistics for Arousal Control Words in Study 1

\begin{tabular}{lllll}
\hline Arousal Control Words & $M$ & $S D$ & $n$ & Warriner Norms \\
\hline Emergency & 8.29 & 1.20 & 76 & $6.43(2.73)$ \\
Earthquake & 8.25 & 1.11 & 76 & $6.76(2.39)$ \\
Furious & 8.25 & 1.12 & 76 & $6.09(2.17)$ \\
Dangerous & 8.12 & 1.02 & 76 & $6.81(2.34)$ \\
Sex & 8.04 & 1.35 & 76 & $7.6(2.01)$ \\
Assault & 8.00 & 1.27 & 76 & $6.8(2.11)$ \\
Robber & 7.75 & 1.17 & 76 & $6.2(2.21)$ \\
Erotic & 7.64 & 1.31 & 76 & $7.27(2.51)$ \\
Suicide & 7.54 & 1.65 & 76 & $6.21(2.67)$ \\
Shotgun & 7.47 & 1.33 & 76 & $6.55(2.22)$ \\
Rock & 3.97 & 2.34 & 76 & $3.14(2.29)$
\end{tabular}

table continues 


\begin{tabular}{lllll}
\hline Arousal Control Words & $M$ & $S D$ & $n$ & Warriner Norms \\
\hline Valley & $\mathbf{3 . 2 4}$ & $\mathbf{1 . 7 5}$ & $\mathbf{7 6}$ & $\mathbf{2 . 7}(\mathbf{1 . 8 4})$ \\
Statue & 2.67 & 1.73 & 76 & $5.95(1.35)$ \\
Vegetable & 2.67 & 1.83 & 76 & $3.75(2.83)$ \\
\hline
\end{tabular}


Table D-6

Descriptive Statistics for Valence Calibrator Words in Study 1

\begin{tabular}{lllll}
\hline Valence Calibrator Words & $M$ & $S D$ & $n$ & Warriner Norms \\
\hline Laughter & 8.34 & 1.16 & 112 & $8.05(1.57)$ \\
Accomplishment & 8.20 & 1.02 & 112 & $8.05(0.86)$ \\
Hug & 7.97 & 1.37 & 112 & $8.23(0.87)$ \\
Mechanic & 5.23 & 1.41 & 112 & $5.45(1.32)$ \\
Maintenance & 4.75 & 1.15 & 112 & $5.95(1.76)$ \\
Small & 4.42 & 1.28 & 112 & $5.76(2.02)$ \\
Leukemia & 1.34 & .94 & 112 & $1.47(1.39)$ \\
Massacre & 1.31 & 1.14 & 112 & $1.77(1.57)$ \\
Terrorism & 1.25 & .72 & 112 & $1.60(1.23)$ \\
\hline
\end{tabular}


Table D-7

Descriptive Statistics for Arousal Calibrator Words in Study 1

\begin{tabular}{lllll}
\hline Arousal Calibrator Words & $M$ & $S D$ & $n$ & Warriner Norms \\
Attack & 7.82 & 1.26 & 76 & $7.05(2.11)$ \\
Party & 7.38 & 1.58 & 76 & $6.08(2.80)$ \\
Rebellious & 6.93 & 1.45 & 76 & $6.45(1.93)$ \\
Eat & 5.22 & 1.76 & 76 & $4.38(2.79)$ \\
Soda & 5.08 & 1.66 & 76 & $4.77(2.27)$ \\
Cat & 4.38 & 2.11 & 76 & $4.50(2.48)$ \\
Breath & 2.72 & 1.73 & 76 & $2.35(1.90)$ \\
Tea & 2.45 & 1.54 & 76 & $2.05(1.43)$ \\
Meditation & 1.42 & .88 & 76 & $2.50(1.99)$ \\
\hline
\end{tabular}


Table D-8

Summary of Descriptive Statistics for ABA Terms in Study 2

\begin{tabular}{|c|c|c|c|c|c|c|c|c|}
\hline & & & & & $\begin{array}{l}\text { Correlation } \\
\text { Between } \\
\text { Spanish and } \\
\text { English } \\
\text { Ratings }\end{array}$ & $\begin{array}{l}\text { Correlation } \\
\text { Between } \\
\text { Difference } \\
\text { Score and } \\
\text { Acculturation }\end{array}$ & $\begin{array}{c}\text { Correlation } \\
\text { Between } \\
\text { Difference Score } \\
\text { and Language } \\
\text { Preference } \\
\text { (Angry) }\end{array}$ & $\begin{array}{c}\text { Correlation } \\
\text { Between } \\
\text { Difference Score } \\
\text { and Language } \\
\text { Preference } \\
\text { (Happy) }\end{array}$ \\
\hline $\begin{array}{l}\text { ABA Term in English } \\
\text { ABA Term in Spanish }\end{array}$ & $M$ & $S D$ & $t$ & $p$ & $r$ & $r$ & $r$ & $r$ \\
\hline Positive Reinforcement & 7.23 & 1.39 & -.06 & .95 & $.56^{*}$ & .01 & $.13^{*}$ & .18 \\
\hline Reforzamiento Positivo & 7.24 & 1.59 & & & & & & \\
\hline Satiation & 6.02 & 1.69 & 1.57 & .12 & $.34 *$ & -.04 & .01 & .09 \\
\hline Saciedad & 5.74 & 1.78 & & & & & & \\
\hline Stimulus & 5.82 & 1.47 & .33 & .74 & $.55^{*}$ & $-.24 * *$ & -.07 & -.11 \\
\hline Estimulo & 5.78 & 1.38 & & & & & & \\
\hline Motivating Operation & 5.80 & 1.59 & - & .26 & $.40^{*}$ & -.00 & -.15 & .01 \\
\hline Operación Motivacional & 5.98 & 1.57 & 1.14 & & & & & \\
\hline Escape & 5.64 & 1.94 & .48 & .63 & $.46^{*}$ & -.01 & -.00 & -.07 \\
\hline Escapé & 5.56 & 1.98 & & & & & & \\
\hline Function & 5.60 & 1.26 & -.81 & .42 & $.59 *$ & -.00 & -.06 & -.01 \\
\hline Función & 5.68 & 1.40 & & & & & & \\
\hline Behavior & 5.56 & 1.32 & .60 & .55 & $.45^{*}$ & -.03 & .02 & .17 \\
\hline Conducta & 5.49 & 1.22 & & & & & & \\
\hline
\end{tabular}




\begin{tabular}{|c|c|c|c|c|c|c|c|c|}
\hline & & & & & $\begin{array}{l}\text { Correlation } \\
\text { Between } \\
\text { Spanish and } \\
\text { English } \\
\text { Ratings }\end{array}$ & $\begin{array}{l}\text { Correlation } \\
\text { Between } \\
\text { Difference } \\
\text { Score and } \\
\text { Acculturation }\end{array}$ & $\begin{array}{c}\text { Correlation } \\
\text { Between } \\
\text { Difference Score } \\
\text { and Language } \\
\text { Preference } \\
\text { (Angry) }\end{array}$ & $\begin{array}{c}\text { Correlation } \\
\text { Between } \\
\text { Difference Score } \\
\text { and Language } \\
\text { Preference } \\
\text { (Happy) }\end{array}$ \\
\hline $\begin{array}{l}\text { ABA Term in English } \\
A B A \text { Term in Spanish }\end{array}$ & $M$ & $S D$ & $t$ & $p$ & $r$ & $r$ & $r$ & $r$ \\
\hline Reinforce & 5.52 & 1.50 & - & .31 & $.44^{*}$ & .07 & .16 & .01 \\
\hline Reforzar & 5.68 & 1.76 & 1.03 & & & & & \\
\hline Response & 5.49 & 1.30 & - & .07 & $.35 *$ & -.02 & -.09 & .01 \\
\hline Respuesta & 5.73 & 1.29 & 1.82 & & & & & \\
\hline Shaping & 5.38 & 1.22 & 2.09 & .04 & -.01 & .04 & .02 & -.02 \\
\hline Moldeamiento & 5.06 & 1.27 & & & & & & \\
\hline Preference Assessment & 5.36 & 1.41 & 3.97 & .001 & $.21 *$ & -.07 & -.06 & -.05 \\
\hline Evaluación de Preferencias & 4.76 & 1.22 & & & & & & \\
\hline Establishing Operation & 5.31 & 1.26 & -.06 & .95 & $.35^{*}$ & .05 & .07 & -.00 \\
\hline Operación de & 5.32 & 1.41 & & & & & & \\
\hline \multicolumn{9}{|l|}{ Establecimiento } \\
\hline Target Behavior & 5.25 & 1.61 & - & .11 & .43 & .09 & .02 & -.02 \\
\hline Conducta de Interes & 5.48 & 1.44 & 1.63 & & & & & \\
\hline Elopement & 5.25 & 1.80 & 5.92 & .001 & -.04 & .01 & -.04 & .04 \\
\hline Conducta de Fuga & 3.98 & 1.53 & & & & & & \\
\hline Function of Behavior & 5.22 & 1.38 & -.75 & .46 & $.44^{*}$ & .11 & -.02 & -.02 \\
\hline Función de la Conducta & 5.31 & 1.32 & & & & & & \\
\hline Operational Definition & 5.15 & 1.23 & -.15 & .89 & $.50 *$ & .05 & .14 & .12 \\
\hline Definición Operacional & 5.17 & 1.22 & & & & & & \\
\hline Brief Functional Analysis & 5.10 & 1.26 & -.13 & .89 & $.36^{*}$ & -.04 & -.00 & -.10 \\
\hline Analisis Funcional Breve & 5.11 & 1.10 & & & & & & \\
\hline
\end{tabular}




\begin{tabular}{|c|c|c|c|c|c|c|c|c|}
\hline & & & & & $\begin{array}{l}\text { Correlation } \\
\text { Between } \\
\text { Spanish and } \\
\text { English } \\
\text { Ratings }\end{array}$ & $\begin{array}{c}\text { Correlation } \\
\text { Between } \\
\text { Difference } \\
\text { Score and } \\
\text { Acculturation }\end{array}$ & $\begin{array}{c}\text { Correlation } \\
\text { Between } \\
\text { Difference Score } \\
\text { and Language } \\
\text { Preference } \\
\text { (Angry) }\end{array}$ & $\begin{array}{c}\text { Correlation } \\
\text { Between } \\
\text { Difference Score } \\
\text { and Language } \\
\text { Preference } \\
\text { (Happy) }\end{array}$ \\
\hline$A B A$ Term in Spanish & $M$ & $S D$ & $t$ & $p$ & $r$ & $r$ & $r$ & $r$ \\
\hline Task Analysis & 5.07 & 1.48 & .96 & .34 & $.55^{*}$ & .08 & .00 & -.02 \\
\hline Analisis de Tarea & 4.95 & 1.48 & & & & & & \\
\hline Token Economy & 4.86 & 1.34 & -.42 & .68 & $.36^{*}$ & .03 & .06 & -.05 \\
\hline Economia de Fichas & 4.91 & 1.32 & & & & & & \\
\hline Contingency & 4.86 & 1.54 & .99 & .92 & $.27 *$ & .03 & -.02 & -.14 \\
\hline Contingencia & 4.84 & 1.47 & & & & & & \\
\hline Reinforcement Schedule & 4.85 & 1.55 & -1.62 & .11 & $.38^{*}$ & .14 & $.14^{*}$ & .23 \\
\hline Programa de Reforzamiento & 5.11 & 1.70 & & & & & & \\
\hline Antecedent & 4.84 & 1.24 & .77 & .45 & $.41^{*}$ & .02 & -.04 & -.05 \\
\hline Antecendente & 4.75 & 1.33 & & & & & & \\
\hline Early Intensive BI & 4.70 & 1.33 & .82 & .42 & $.49 *$ & -.01 & -.02 & -.05 \\
\hline Intervención Conductal TI & 4.58 & 1.61 & & & & & & \\
\hline Generalization & 4.69 & 1.58 & -1.99 & .05 & $.54^{*}$ & -.04 & -.09 & -.17 \\
\hline Generelización & 4.94 & 1.37 & & & & & & \\
\hline Differential Reinforcement & 4.62 & 1.43 & -2.14 & .03 & $.38 *$ & -.12 & -.03 & -.05 \\
\hline Reforzamineto Diferecial & 4.91 & 1.33 & & & & & & \\
\hline Chain & 4.23 & 1.65 & .06 & .95 & $.58 *$ & .00 & .03 & .05 \\
\hline Cadena & 4.22 & 1.73 & & & & & & \\
\hline Delayed Reinforcement & 4.10 & 1.66 & -1.07 & .29 & $.26^{*}$ & .12 & .01 & -.02 \\
\hline Reforzamiento Demorado & 4.29 & 1.61 & & & & & & \\
\hline
\end{tabular}

table continues 


\begin{tabular}{|c|c|c|c|c|c|c|c|c|}
\hline & & & & & $\begin{array}{c}\text { Correlation } \\
\text { Between } \\
\text { Spanish and } \\
\text { English } \\
\text { Ratings }\end{array}$ & $\begin{array}{l}\text { Correlation } \\
\text { Between } \\
\text { Difference } \\
\text { Score and } \\
\text { Acculturation }\end{array}$ & $\begin{array}{c}\text { Correlation } \\
\text { Between } \\
\text { Difference Score } \\
\text { and Language } \\
\text { Preference } \\
\text { (Angry) }\end{array}$ & $\begin{array}{c}\text { Correlation } \\
\text { Between } \\
\text { Difference Score } \\
\text { and Language } \\
\text { Preference } \\
\text { (Happy) }\end{array}$ \\
\hline $\begin{array}{l}\text { ABA Term in English } \\
A B A \text { Term in Spanish }\end{array}$ & $M$ & $S D$ & $t$ & $p$ & $r$ & $r$ & $r$ & $r$ \\
\hline Time-Out & 4.09 & 1.88 & -2.30 & .02 & $.38^{*}$ & -.02 & -.05 & -.09 \\
\hline Tiempo Fuera & 4.52 & 1.95 & & & & & & \\
\hline Consequence & 4.02 & 1.88 & .00 & 1.00 & $.47 *$ & -.17 & -.04 & -.15 \\
\hline Consecuencia & 4.02 & 1.81 & & & & & & \\
\hline Stereotypy & 3.60 & 1.80 & -1.67 & .10 & $.44^{*}$ & .02 & .09 & .12 \\
\hline Estereotipia & 3.88 & 1.82 & & & & & & \\
\hline Incompatible Behavior & 3.00 & 1.52 & -2.11 & .04 & $.48^{*}$ & .13 & .08 & -.03 \\
\hline Conducta Incompatible & 3.29 & 1.55 & & & & & & \\
\hline Negative Reinforcement & 2.60 & 1.70 & .26 & .80 & $.68^{*}$ & .08 & -.10 & -.06 \\
\hline Reforzamiento Negativo & 2.57 & 1.72 & & & & & & \\
\hline Deprivation & 2.33 & 1.62 & -7.38 & .001 & .16 & -.01 & -.15 & -.15 \\
\hline Privación & 4.01 & 2.25 & & & & & & \\
\hline Extinction & 2.25 & 1.88 & -.87 & .39 & $.75^{*}$ & -.02 & .09 & .04 \\
\hline Extinción & 2.35 & 1.92 & & & & & & \\
\hline Punishment & 2.22 & 1.62 & -1.15 & .25 & $.50^{*}$ & -.01 & -.04 & .01 \\
\hline Castigo & 2.40 & 1.78 & & & & & & \\
\hline Discrimination & 1.86 & 1.41 & -1.57 & .12 & $.60^{*}$ & .04 & -.01 & .04 \\
\hline Discriminación & 2.03 & 1.38 & & & & & & \\
\hline
\end{tabular}


Table D-9

Summary of Descriptive Statistics for General Psychological Terms in Study 2

\begin{tabular}{|c|c|c|c|c|c|c|c|c|}
\hline & & & & & $\begin{array}{c}\text { Correlation } \\
\text { Between } \\
\text { Spanish and } \\
\text { English } \\
\text { Ratings }\end{array}$ & $\begin{array}{l}\text { Correlation } \\
\text { Between } \\
\text { Difference } \\
\text { Score and } \\
\text { Acculturation }\end{array}$ & $\begin{array}{c}\text { Correlation } \\
\text { Between } \\
\text { Difference Score } \\
\text { and Language } \\
\text { Preference } \\
\text { (Angry) }\end{array}$ & $\begin{array}{c}\text { Correlation } \\
\text { Between } \\
\text { Difference Score } \\
\text { and Language } \\
\text { Preference } \\
\text { (Happy) }\end{array}$ \\
\hline Term & $M$ & $S D$ & $t$ & $p$ & $r$ & $r$ & $r$ & $r$ \\
\hline Reward & 8.00 & 1.28 & 6.27 & .001 & $.43 * *$ & .13 & .13 & .13 \\
\hline Recompensa & 7.06 & 1.77 & & & & & & \\
\hline Praise & 7.53 & 1.55 & 4.98 & .001 & $.39 * *$ & .04 & $.24 * *$ & .12 \\
\hline Alabanza & 6.68 & 1.91 & & & & & & \\
\hline Incentive & 6.82 & 1.82 & -.79 & .43 & $.59 * *$ & .04 & .09 & .03 \\
\hline Incentivo & 6.94 & 1.67 & & & & & & \\
\hline Empathy & 6.71 & 2.07 & -.05 & .96 & $.56 * *$ & .03 & .05 & .05 \\
\hline Empatia & 6.71 & 1.77 & & & & & & \\
\hline Feeling & 6.06 & 1.61 & -.74 & .46 & $.44 * *$ & -.10 & -.04 & .01 \\
\hline Sentimiento & 6.18 & 1.77 & & & & & & \\
\hline Play Therapy & 5.98 & 1.44 & 3.37 & .001 & $.46^{* *}$ & -.15 & $-.22 *$ & -.13 \\
\hline Terapia Ludica & 5.44 & 1.76 & & & & & & \\
\hline Emotion & 5.96 & 1.57 & -2.56 & .01 & $.63 * *$ & -.01 & .10 & .12 \\
\hline Emoción & 6.27 & 1.47 & & & & & & \\
\hline Plan & 5.94 & 1.38 & -2.48 & .01 & $.52 * *$ & .11 & .03 & .01 \\
\hline Plan & 6.25 & 1.47 & & & & & & \\
\hline
\end{tabular}




\begin{tabular}{|c|c|c|c|c|c|c|c|c|}
\hline & & & & & $\begin{array}{l}\text { Correlation } \\
\text { Between } \\
\text { Spanish and } \\
\text { English } \\
\text { Ratings }\end{array}$ & $\begin{array}{l}\text { Correlation } \\
\text { Between } \\
\text { Difference } \\
\text { Score and } \\
\text { Acculturation }\end{array}$ & $\begin{array}{c}\text { Correlation } \\
\text { Between } \\
\text { Difference Score } \\
\text { and Language } \\
\text { Preference } \\
\text { (Angry) }\end{array}$ & $\begin{array}{c}\text { Correlation } \\
\text { Between } \\
\text { Difference Score } \\
\text { and Language } \\
\text { Preference } \\
\text { (Happy) }\end{array}$ \\
\hline Term & $M$ & $S D$ & $t$ & $p$ & $r$ & $r$ & $r$ & $r$ \\
\hline Confidentiality & 5.90 & 1.67 & .24 & .81 & $.58 * *$ & .11 & .02 & .06 \\
\hline Confidencial & 5.87 & 1.59 & & & & & & \\
\hline Obedience & 5.63 & 1.93 & -3.19 & .001 & $.70 * *$ & -.00 & .01 & .00 \\
\hline Obediente & 6.03 & 1.73 & & & & & & \\
\hline Treatment & 5.61 & 1.56 & 1.20 & .23 & $.33 * *$ & -.06 & -.00 & -.01 \\
\hline Tratamiento & 5.44 & 1.21 & & & & & & \\
\hline Therapy & 5.60 & 1.71 & .12 & .91 & $.59 * *$ & .06 & -.15 & -.06 \\
\hline Terapia & 5.58 & 1.59 & & & & & & \\
\hline Adjustment & 5.57 & 1.45 & 1.31 & .19 & $.44 * *$ & -.07 & -.15 & -.03 \\
\hline Ajuste & 5.40 & 1.23 & & & & & & \\
\hline Counseling & 5.40 & 1.74 & -1.12 & .26 & $.36 * *$ & -.13 & -.07 & -.08 \\
\hline Asesoramiento & 5.57 & 1.31 & & & & & & \\
\hline Client & 5.38 & 1.46 & -1.83 & .07 & $.65 * *$ & -.04 & -.16 & -.17 \\
\hline Cliente & 5.58 & 1.46 & & & & & & \\
\hline Mood & 5.37 & 1.47 & -9.78 & .001 & $.20 *$ & .07 & .12 & .12 \\
\hline Animo & 7.13 & 1.74 & & & & & & \\
\hline Referral & 5.33 & 1.47 & .00 & 1.00 & $.33 * *$ & -.05 & -.11 & -1.0 \\
\hline Referencia & 5.33 & 1.28 & & & & & & \\
\hline
\end{tabular}




\begin{tabular}{|c|c|c|c|c|c|c|c|c|}
\hline & & & & & $\begin{array}{c}\text { Correlation } \\
\text { Between } \\
\text { Spanish and } \\
\text { English } \\
\text { Ratings }\end{array}$ & $\begin{array}{l}\text { Correlation } \\
\text { Between } \\
\text { Difference } \\
\text { Score and } \\
\text { Acculturation }\end{array}$ & $\begin{array}{c}\text { Correlation } \\
\text { Between } \\
\text { Difference Score } \\
\text { and Language } \\
\text { Preference } \\
\text { (Angry) }\end{array}$ & $\begin{array}{c}\text { Correlation } \\
\text { Between } \\
\text { Difference Score } \\
\text { and Language } \\
\text { Preference } \\
\text { (Happy) }\end{array}$ \\
\hline $\begin{array}{l}\text { General Psychological } \\
\text { Term }\end{array}$ & $M$ & $S D$ & $t$ & $p$ & $r$ & $r$ & $r$ & $r$ \\
\hline $\begin{array}{l}\text { Behavior Modification } \\
\text { Modificación de } \\
\text { Comportamiento }\end{array}$ & $\begin{array}{l}4.83 \\
4.88\end{array}$ & $\begin{array}{l}1.49 \\
1.67\end{array}$ & -.43 & .67 & $.59 * *$ & .07 & $.19^{*}$ & .14 \\
\hline $\begin{array}{l}\text { Risk Factors } \\
\text { Factores de Riesgo }\end{array}$ & $\begin{array}{l}3.75 \\
3.81\end{array}$ & $\begin{array}{l}1.78 \\
1.60\end{array}$ & -.29 & .77 & $.21^{*}$ & 1.0 & .06 & .02 \\
\hline $\begin{array}{l}\text { Learned Helplessness } \\
\text { Indefensión apredinda }\end{array}$ & $\begin{array}{l}3.35 \\
4.05\end{array}$ & $\begin{array}{l}1.93 \\
1.73\end{array}$ & -3.33 & .001 & $.22 *$ & -.14 & -.05 & $-.24 * *$ \\
\hline $\begin{array}{l}\text { Denial } \\
\text { Negación }\end{array}$ & $\begin{array}{l}2.90 \\
2.90\end{array}$ & $\begin{array}{l}1.64 \\
1.64\end{array}$ & .05 & .96 & $.37 * *$ & .05 & .02 & 1.0 \\
\hline $\begin{array}{l}\text { Delusion } \\
\text { Delirante }\end{array}$ & $\begin{array}{l}2.79 \\
3.90\end{array}$ & $\begin{array}{l}1.79 \\
1.92\end{array}$ & -5.73 & .001 & $.31 * *$ & -.04 & -.04 & -.13 \\
\hline $\begin{array}{l}\text { Tantrum } \\
\text { Berrinche }\end{array}$ & $\begin{array}{l}2.67 \\
2.75\end{array}$ & $\begin{array}{l}1.89 \\
1.79\end{array}$ & -.45 & .65 & $.42 * *$ & -.05 & $-.21 *$ & $-.18^{*}$ \\
\hline $\begin{array}{l}\text { Disorder } \\
\text { Trastorno }\end{array}$ & $\begin{array}{l}2.44 \\
2.81\end{array}$ & $\begin{array}{l}1.59 \\
1.88\end{array}$ & -2.01 & .04 & $.37 * *$ & -.15 & -.09 & -1.0 \\
\hline $\begin{array}{l}\text { Chronic Stress } \\
\text { Estresores Cronicos }\end{array}$ & $\begin{array}{l}2.39 \\
2.62\end{array}$ & $\begin{array}{l}1.70 \\
1.76\end{array}$ & -1.45 & .15 & $.51 * *$ & -.08 & -.16 & -.12 \\
\hline $\begin{array}{l}\text { Penalty } \\
\text { Castigo }\end{array}$ & $\begin{array}{l}2.33 \\
2.27\end{array}$ & $\begin{array}{l}1.57 \\
1.72\end{array}$ & .35 & .73 & $.40 * *$ & .00 & -.13 & .03 \\
\hline $\begin{array}{l}\text { Prejudice } \\
\text { Prejucio }\end{array}$ & $\begin{array}{l}2.31 \\
2.51\end{array}$ & $\begin{array}{l}1.66 \\
1.72\end{array}$ & -1.70 & .09 & $.70 * *$ & .08 & -.01 & .02 \\
\hline $\begin{array}{l}\text { Anxiety } \\
\text { Anciedad }\end{array}$ & $\begin{array}{l}2.09 \\
2.40\end{array}$ & $\begin{array}{l}1.52 \\
1.60\end{array}$ & -2.13 & .04 & $.45^{* *}$ & -.04 & -.06 & -.11 \\
\hline
\end{tabular}




\begin{tabular}{|c|c|c|c|c|c|c|c|c|}
\hline & & & & & $\begin{array}{l}\text { Correlation } \\
\text { Between } \\
\text { Spanish and } \\
\text { English } \\
\text { Ratings }\end{array}$ & $\begin{array}{l}\text { Correlation } \\
\text { Between } \\
\text { Difference } \\
\text { Score and } \\
\text { Acculturation }\end{array}$ & $\begin{array}{c}\text { Correlation } \\
\text { Between } \\
\text { Difference Score } \\
\text { and Language } \\
\text { Preference } \\
\text { (Angry) }\end{array}$ & $\begin{array}{c}\text { Correlation } \\
\text { Between } \\
\text { Difference Score } \\
\text { and Language } \\
\text { Preference } \\
\text { (Happy) }\end{array}$ \\
\hline Term & $M$ & $S D$ & $t$ & $p$ & $r$ & $r$ & $r$ & $r$ \\
\hline Addiction & 2.06 & 1.76 & .28 & .78 & $.70 * *$ & .01 & -.06 & -.06 \\
\hline Adicción & 2.03 & 1.44 & & & & & & \\
\hline Stress & 2.01 & 1.47 & -2.00 & .05 & $.53 * *$ & -.04 & -.03 & -1.0 \\
\hline Estres & 2.27 & 1.56 & & & & & & \\
\hline Substance Abuse & 1.85 & 1.34 & -.45 & .65 & $.54 * *$ & .06 & .00 & -.07 \\
\hline Abusos de Sustancias & 1.90 & 1.52 & & & & & & \\
\hline Depression & 1.48 & 1.26 & -1.03 & .30 & $.57 * *$ & -.01 & -.04 & -.12 \\
\hline Depresión & 1.59 & 1.10 & & & & & & \\
\hline
\end{tabular}


Table D-10

Summary of Descriptive Statistics for Control Words in Study 2

\begin{tabular}{|c|c|c|c|c|c|c|c|c|}
\hline & & & & & $\begin{array}{c}\text { Correlation } \\
\text { Between } \\
\text { Spanish and } \\
\text { English Ratings }\end{array}$ & $\begin{array}{c}\text { Correlation } \\
\text { Between } \\
\text { Difference Score } \\
\text { and } \\
\text { Acculturation }\end{array}$ & $\begin{array}{c}\text { Correlation } \\
\text { Between } \\
\text { Difference Score } \\
\text { and Language } \\
\text { Preference } \\
\text { (Angry) }\end{array}$ & $\begin{array}{c}\text { Correlation } \\
\text { Between } \\
\text { Difference Score } \\
\text { and Language } \\
\text { Preference } \\
\text { (Happy) }\end{array}$ \\
\hline Control Words & $M$ & $S D$ & $t$ & $p$ & $r$ & $r$ & $r$ & $r$ \\
\hline Vacation & 8.27 & 1.21 & 5.79 & .001 & $.50 * *$ & -.00 & .08 & -.04 \\
\hline Viaje & 7.48 & 1.70 & & & & & & \\
\hline Freedom & 8.20 & 1.46 & 1.98 & .05 & $.59 * *$ & -.01 & -.05 & .03 \\
\hline Libre & 7.96 & 1.54 & & & & & & \\
\hline Healthy & 8.21 & 1.31 & 4.52 & .001 & $.55 * *$ & .02 & .16 & .06 \\
\hline Sano & 7.59 & 1.83 & & & & & & \\
\hline Smile & 8.08 & 1.47 & -.32 & .75 & $.50 * *$ & .05 & .07 & .11 \\
\hline Sonreir & 8.12 & 1.35 & & & & & & \\
\hline Succeed & 8.06 & 1.40 & 2.47 & .02 & $.47 * *$ & .03 & .11 & .03 \\
\hline Triunfar & 7.68 & 1.87 & & & & & & \\
\hline Sunshine & 7.96 & 1.43 & 6.89 & .001 & $.38 * *$ & .01 & .05 & .06 \\
\hline Soleado & 6.68 & 2.16 & & & & & & \\
\hline Relax & 7.94 & 1.39 & 1.61 & .11 & $.68 * *$ & .02 & .01 & -.05 \\
\hline Relajar & 7.77 & 1.53 & & & & & & \\
\hline
\end{tabular}

table continues 


\begin{tabular}{|c|c|c|c|c|c|c|c|c|}
\hline & & & & & $\begin{array}{c}\text { Correlation } \\
\text { Between } \\
\text { Spanish and } \\
\text { English Ratings }\end{array}$ & $\begin{array}{c}\text { Correlation } \\
\text { Between } \\
\text { Difference Score } \\
\text { and } \\
\text { Acculturation }\end{array}$ & $\begin{array}{c}\text { Correlation } \\
\text { Between } \\
\text { Difference Score } \\
\text { and Language } \\
\text { Preference } \\
\text { (Angry) }\end{array}$ & $\begin{array}{c}\text { Correlation } \\
\text { Between } \\
\text { Difference Score } \\
\text { and Language } \\
\text { Preference } \\
\text { (Happy) }\end{array}$ \\
\hline Control Words & $M$ & $S D$ & $t$ & $p$ & $r$ & $r$ & $r$ & $r$ \\
\hline Summer & 7.75 & 1.49 & 1.56 & .12 & $.79 * *$ & -.03 & .16 & .10 \\
\hline Verano & 7.61 & 1.62 & & & & & & \\
\hline Knowledgeable & 7.48 & 1.55 & 2.59 & .01 & $.51 * *$ & .15 & $.20 *$ & .07 \\
\hline Sabiduria & 7.10 & 1.71 & & & & & & \\
\hline Joke & 7.43 & 1.47 & -.64 & .52 & $.47^{* *}$ & -.09 & -.07 & .03 \\
\hline Chiste & 7.52 & 1.72 & & & & & & \\
\hline Dream & 7.32 & 1.59 & 3.64 & .001 & $.53 * *$ & -.04 & -.07 & -.08 \\
\hline Soñar & 6.80 & 1.70 & & & & & & \\
\hline Give & 7.18 & 1.58 & 2.02 & .05 & $.45^{* *}$ & $.19^{*}$ & .02 & -.04 \\
\hline Regalar & 6.87 & 1.70 & & & & & & \\
\hline Jail & 1.74 & 1.45 & -2.36 & .02 & $.57 * *$ & -04 & -.09 & .02 \\
\hline Carcel & 2.04 & 1.63 & & & & & & \\
\hline
\end{tabular}


Table D-11

Summary of Descriptive Statistics for Calibrator Words in Study 2

\begin{tabular}{|c|c|c|c|c|c|c|c|c|}
\hline & & & & & $\begin{array}{c}\text { Correlation } \\
\text { Between } \\
\text { Spanish and } \\
\text { English Ratings }\end{array}$ & $\begin{array}{l}\text { Correlation } \\
\text { Between } \\
\text { Difference } \\
\text { Score and } \\
\text { Acculturation }\end{array}$ & $\begin{array}{c}\text { Correlation } \\
\text { Between Difference } \\
\text { Score and } \\
\text { Language } \\
\text { Preference (Angry) }\end{array}$ & $\begin{array}{c}\text { Correlation } \\
\text { Between } \\
\text { Difference Score } \\
\text { and Language } \\
\text { Preference } \\
\text { (Happy) }\end{array}$ \\
\hline Calibrator Words & $M$ & $S D$ & $t$ & $p$ & $r$ & $r$ & $r$ & $r$ \\
\hline Laughter & 8.12 & 1.43 & 1.19 & .24 & $.37 * *$ & .04 & -.07 & .05 \\
\hline Risa & 7.94 & 1.62 & & & & & & \\
\hline Hug & 8.05 & 1.33 & .66 & .51 & $.35^{* *}$ & .07 & .12 & $.18^{*}$ \\
\hline Abrazo & 7.95 & 1.51 & & & & & & \\
\hline Accomplishment & 7.96 & 1.51 & 3.23 & .002 & $.54 * *$ & .16 & .05 & .08 \\
\hline Logro & 7.50 & 1.77 & & & & & & \\
\hline Mechanic & 5.28 & 1.21 & .49 & .63 & $.60 * *$ & .03 & -.01 & -.09 \\
\hline Mecanico & 5.23 & 1.25 & & & & & & \\
\hline Maintenance & 5.25 & 1.49 & -2.19 & .03 & $.51 * *$ & -.06 & -.08 & -.02 \\
\hline Mantenimiento & 5.53 & 1.40 & & & & & & \\
\hline Small & 4.79 & 1.48 & -2.55 & .01 & $.24 * *$ & -.04 & -.05 & -.04 \\
\hline Реqueño & 5.20 & 1.41 & & & & & & \\
\hline Massacre & 1.44 & 1.38 & 1.10 & .27 & $.61 * *$ & .02 & -.02 & -.02 \\
\hline Masacre & 1.55 & 1.15 & & & & & & \\
\hline
\end{tabular}




\begin{tabular}{|c|c|c|c|c|c|c|c|c|}
\hline & & & & & $\begin{array}{c}\text { Correlation } \\
\text { Between } \\
\text { Spanish and } \\
\text { English Ratings }\end{array}$ & $\begin{array}{l}\text { Correlation } \\
\text { Between } \\
\text { Difference } \\
\text { Score and } \\
\text { Acculturation }\end{array}$ & $\begin{array}{c}\text { Correlation } \\
\text { Between Difference } \\
\text { Score and } \\
\text { Language } \\
\text { Preference (Angry) }\end{array}$ & $\begin{array}{c}\text { Correlation } \\
\text { Between } \\
\text { Difference Score } \\
\text { and Language } \\
\text { Preference } \\
\text { (Happy) }\end{array}$ \\
\hline Calibrator Words & $M$ & $S D$ & $t$ & $p$ & $r$ & $r$ & $r$ & $r$ \\
\hline Terrorism & 1.44 & 1.27 & -.20 & .84 & $.38 * *$ & -.10 & -.02 & -.12 \\
\hline Terrorismo & 1.47 & 1.17 & & & & & & \\
\hline Leukemia & 1.40 & .98 & -2.49 & .01 & $.41 * *$ & .12 & .06 & .15 \\
\hline Leucemia & 1.70 & 1.39 & & & & & & \\
\hline
\end{tabular}

$* p<.05$

$* * p<.001$ 